\title{
PANORÁMICA DE LA TRANSPARENCIA EN EL ESTADO Y LA TENDENCIA DEL DERECHO DE ACCESO A LA INFORMACIÓN PÚBLICA EN ESPAÑA
}

\author{
PANORAMA OF TRANSPARENCY IN THE STATE AND THE \\ TREND OF THE RIGHT TO ACCESS TO PUBLIC \\ INFORMATION IN SPAIN
}

\author{
MANUEL PALOMARES HERRERA*
}

Recibido: 27/02/2017

Aceptado: 22/05/2017

\begin{abstract}
SUMARIO: I.- INTRODUCCIÓN. II.- PANORÁMICA ESTATAL DE LA TRANSPARENCIA. 1. Transparencia por poderes. A) En el Poder Legislativo. B) En El Poder Judicial. C) En EL PODER EJECUTIVO. 2. OtROS ENTES AUTÓNOMOS DEL ESTADO. 3. BREVE REFERENCIA A LA TRANSPARENCIA EN LAS CCAA. III.- ANCLAJE Y TENDENCIA DEL DERECHO DE ACCESO A LA INFORMACIÓN. 1. ANCLAJE CONSTITUCIONAL DEL DERECHO DE ACCESO A LA INFORMACIÓN. 2. IUSFUNDAMENTALIZACIÓN DEL DERECHO DESDE LA VINCULACIÓN INSTRUMENTAL Y COMO DERECHO AUTÓNOMO. IV.- CONCLUSIONES. V.- BIBLIOGRAFÍA.
\end{abstract}

SUMMARY: I. INTRODUCTION. II.- STATE PANORAMICS OF TRANSPARENCY. 1. TRANSPARENCY BY PROXY. A) In THE Legislative POWER. B) IN THE Judicial BRANCH. C) IN THE EXECUTIVE BRANCH. 2. OtHer AUTONOMOUS ENTITIES OF THE STATE. 3. BRIEF REFERENCE TO TRANSPARENCY IN THE AutONOMOUS COMMUNITIES. III.- ANCHORAGE AND TREND OF THE RIGHT OF ACCESS TO INFORMATION. 1. CONSTITUTIONAL ANCHORING OF THE RIGHT OF ACCESS TO INFORMATION. 2. THE DEEPENING OF THE LAW FROM THE INSTRUMENTAL LINKAGE AND AS AN AUTONOMOUS RIGHT. IV.CONCLUSIONS. V.- BIBLIOGRAPHY.

Resumen: La transparencia es una materia jurídica que en los últimos días, por su carácter transversal, alcanza el nivel de mainstreaming. El artículo presenta, clasifica, estudia y comenta todas las regulaciones, acciones y normativas en materia de transparencia y acceso a la información pública en cada uno de los Poderes del Estado español. A continuación, desde el cuestionamiento del anclaje constitucional del derecho que se estudia, se expone la actual tendencia iusfundamental del derecho de acceso a la información pública por parte de la doctrina así como consideraciones propias al respecto. El artículo ofrece una perspectiva general de la transparencia en España tanto antes como después de la Ley 19/2013 de 9 de diciembre de Transparencia, Acceso a la Información Pública y Buen Gobierno (En adelante LTBG) así como la posibilidad de elevar el derecho de acceso a la información pública a la categoría de derecho fundamental.

Palabras clave: transparencia, derecho fundamental, derecho de acceso, Estado, información pública.

\footnotetext{
* Doctor en Derecho Público por la Universidad de Jaén
} 
Abstract: Transparency is a legal matter that in recent days, due to its transverse nature, reaches the level of mainstreaming. The article presents, classifies, studies and comments on all regulations and regulations regarding transparency and access to public information in each of the powers of the Spanish State. Then, from the questioning of the constitutional anchoring of the right under study, the current fundamental trend of the right of access to public information by the doctrine and its own considerations are exposed. The article offers an overview of transparency in Spain both before and after Law 19/2013 of December 9 of Transparency, Access to Public Information and Good Governance (hereinafter LTBG) as well as the possibility of raising the right of Access to public information to the category of fundamental right.

Keywords: transparency, fundamental rights, right of access, State, public information.

\section{I.- INTRODUCCIÓN}

Desde la publicación de la $\mathrm{LTBG}^{1}$, la cual desarrolla el acceso a la información consagrado en el art. 105 de la Constitución Española de 1978 (En adelante CE), además de lo propio en transparencia y buen gobierno, ha estallado un maremágnum de elementos en transparencia tan transversal que ha alcanzado a discursos, leyes, reglamentos, estatutos de diferentes organismos, empresas privadas hasta nuestros días creando un auténtico mainstreaming. Además el último informe estadístico del Portal de Transparencia pone de manifiesto de nuevo el incremento paulatino de solicitudes anuales de información pública por parte de ciudadanos lo cual denota una creciente cultura de la transparencia. ${ }^{2}$ Ante esta nueva circunstancia, se plantean las siguientes cuestiones: ¿Cuál era el escenario en la materia en España antes de la LTBG? ¿Se ejercitaba la transparencia y el derecho de acceso a la información en lo público?, ¿Es este un derecho estático o podría aspirar a ser fundamental?

Hemos de comenzar adelantando que el concepto de transparencia asociado al de Estado democrático está en constante evolución desde hace siglos ${ }^{3}$. El Estado de la trasparencia, totalmente probo y reconocedor del derecho fundamental de acceso a la información es el objeto a alcanzar con herramientas como las políticas, normas, iniciativas o medida en transparencia en cada ámbito del Gobierno y la Administración. Esta es la transparencia de Estado. Gracias a la intervención de las Tecnologías de la Información y la Comunicación (TIC's) se superaría el Estado de Bienestar, por lo que puede decirse que es el Estado 3.0 o de tercera generación democrática. Esto, por supuesto también ha influido a la materia de estudio. Este ente persevera en la garantía de todos los derechos y su seguridad jurídica exponiendo la gestión y las actuaciones

\footnotetext{
${ }^{1}$ Boletín Oficial del Estado (BOE) núm. 295, de 10 de diciembre de 2013.

${ }^{2}$ Puede observarse el gráfico de barras en dicho informe, p.12. Disponible en: http://transparencia.gob.es/transparencia/dam/jcr:a0780620-b548-44e9-987e-

fe5886f4b120/2016_12_31_Bolet\%C3\%ADn_Portal_en_cifras-1.pdf (consultado el 19/05/2017).

3،En efecto, hoy en día no puede concebirse una democracia que merezca tal nombre si en ella, además del gobierno de las mayorías y el imperio de la ley, no se garantiza un mínimo control de los ciudadanos sobre la acción de sus gobernantes, más allá de las elecciones periódicas”, RODRIGUEZ ZEPEDA, J., "Estado y transparencia: un paseo por la filosofía política”, Instituto Federal de Acceso a la Información Pública, cuaderno de transparencia 4, 2004, pp. 6-9.
} 
públicas en una comunidad interconectada e intercomunicada. Además alardea, comparte y permite el acceso de la información pública pues la considera res publicae y comunes ómnium, por lo que su consideración la hace ser poseedora de un rango superior al que pueda tener en un Estado que reserve datos de los expuestos en el art. 2 LTBG.

Así, del Estado en su concepto puro, puede decirse que ha desaparecido en favor de una red sistemática de individuos que interactúan donde no es solo la Administración Pública la que influye y media entre los ciudadanos sino que son también los ciudadanos los que influyen en la misma difuminándose cada vez más las diferencias. ${ }^{4}$

Para que un Estado pueda alcanzar el status de transparente, o Estado de la transparencia ha de cumplir requisitos sine qua non y encontrarse en una escala previa: el Estado Social ${ }^{5}$ posterior a un asentado Estado Liberal ${ }^{6}$ y por supuesto de Derecho entendido como "aquel que se rige por un sistema de leyes e instituciones ordenado en

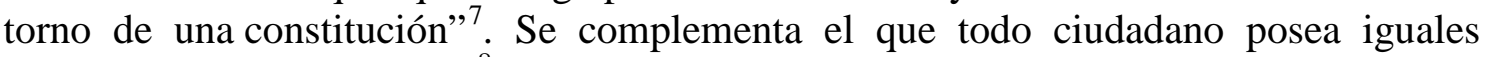
oportunidades de participar ${ }^{8}$ (art. 9 y 23 CE) de las decisiones y que se acceda en igualdad (art. 14 CE) a la información pública.

\section{II.- PANORÁMICA ESTATAL DE LA TRANSPARENCIA}

Para dilucidar qué transparencia de Estado existe en España, veremos a continuación qué medidas, normas, iniciativas y políticas de transparencia y acceso se disponen en cada sector estatal en la actualidad, y las que existían en el Estado antes de 2013.

\footnotetext{
${ }^{4}$ El profesor SÁNCHEZ DE DIEGO facilita una reflexión-idea con la que puede introducirse un concepto del que parte el presente estudio: "Soy de los que entiende que en principio si hablamos de derecho fundamental no podría en absoluto limitarse a la Administración pública, sino que tendría que afectar a todos los poderes del Estado, bien mediante una enunciación singular de cada uno de ellos o bien mediante una enunciación general de todos ellos, como puede ser que afectase a todas las instituciones públicas y privadas que ejerzan una función pública o que se financien con dinero público”. Diario de sesiones de la Comisión del Congreso de los Diputados núm. 254 de 12 de febrero de 2013, p. 27.

${ }^{5}$ Respondiendo según TORRES DEL MORAL a "una idea estatal que busca conjugar jurídicamente su crecimiento con la libertad de los individuos y de los grupos”. TORRES DEL MORAL, A., Estado de Derecho y Democracia de Partidos, Universidad Complutense de Madrid, Madrid, 2010, p.75.

6 "Puede decirse, incluso, que el Estado liberal se puede definir, en sus términos más generales, como un Estado limitado o contenido por las libertades fundamentales de los ciudadanos: un Estado transparente”. RODRIGUEZ ZEPEDA, J., “Estado y transparencia: un paseo por la filosofía política”, Instituto Federal de Acceso a la Información Pública, cuaderno de transparencia 4, 2004, p. 25.

7 MOHL, R., Die deutsche Polizei-wissenschaft nach den Grundsätzen des Rechtsstaates. Tübingen, H. Laupp, 1832, p. 34.

8 "Un gobierno transparente sirve de muy poco si la ciudadanía no es capaz de elevar su nivel de discusión y su capacidad para construir buenas razones y argumentos”. RODRIGUEZ ZEPEDA, J., "Estado y transparencia: un paseo por la filosofía política", Instituto Federal de Acceso a la Información Pública, cuaderno de transparencia 4, 2004, p. 41.
} 
Analizaremos que elementos de acceso y de control $^{9}$ al respecto existen en cada uno de los poderes que separó Montesquieu así como de otros órganos autónomos y elementos que integran el Estado y finalmente una referencia a la transparencia en CCAA.

\section{Transparencia por poderes}

En el presente espacio, y sin perjuicio de señalar lo referente a lo legislativo y ejecutivo en las CCAA en el epígrafe II.3, se desarrolla el estudio que nos ocupa encuadrándose en cada uno de los Poderes del Estado central.

\section{A) En el Poder Legislativo}

Las primeras raíces constitucionales en transparencia se sitúan en la publicidad, entendida positivamente en ese momento, consagrada en la tramitación de leyes en el $\mathrm{BOE}^{10}$, su procedimiento y ahora acentuada con la publicidad del estado de dicha tramitación en el Portal de la Transparencia general y los propios de cada Cámara. Tanto la transparencia en general como su vertiente pasiva, la facultad de que el ciudadano acceda libremente a la información pública, son herramientas democráticas en el sentido de que contribuyen a fiscalizar. ${ }^{11}$

En un análisis de los arts. 72.1 y 80 CE y el Reglamento del Congreso de los Diputados de $1982^{12}$ (RCD) y el del Senado de 1994 y las ilustraciones al respecto de SAINZ MORENO y DÍEZ PICAZO, ${ }^{13}$ extraemos que la publicidad es regla general en los parlamentos por ser la sede de la representación democrática y foro de debate de los asuntos de gobernanza pero se ha de destacar la doble interpretación de ella que hace la Sentencia del Tribunal Constitucional (STC) 136/1989, de 19 de julio al indicar que "existe una publicidad de sesiones y otra publicidad de las deliberaciones y acuerdos adoptados".

Si nos centramos en el aspecto de publicidad de la información susceptible de ser solicitada y alcanzada por el ciudadano, comenzando por el RCD, encontramos preceptos significativos en lo que se refiere a la limitación a la solicitud. Su art. 16 establece que todos los diputados están obligados a "no divulgar las actuaciones que...puedan tener excepcionalmente el carácter de secretas”. Interesa destacar algunos aspectos como que el propio RCD es el que dispone el carácter secreto de determinadas

\footnotetext{
${ }^{9}$ El catedrático LOZANO MIRALLES concluye en un estudio que "la fiscalización se define como el control del sector público, dejando el de la auditoría para el sector privado”. Pues con esta afirmación podemos señalar que la transparencia es una herramienta que ofrece campo de análisis y material de control a la fiscalización y a la auditoría ciudadana. LOZANO MIRALLES, J., “Auditoría pública”, Revista de los Órganos Autónomos de Control Externo, núm. 3, 1995, p. 85.

${ }^{10}$ Disponible en: https://www.boe.es/legislacion/legislacion.php (consultado el 21/4/17).

11 "La fiscalización es una herramienta de trabajo del control parlamentario", LOZANO MIRALLES, J., “Auditoría pública”, Revista de los Órganos Autónomos de Control Externo, núm. 3, 1995, pp. 8445 .

${ }^{12}$ BOE núm. 55, de 5 de marzo de 1982.

${ }^{13}$ Véase SAINZ MORENO, F., Secreto y Transparencia, Estudios para reforma de la reforma de la administración pública, INAP. Madrid, 2004 Y DÍEZ PICAZO, L., Sobre Secretos Oficiales, Civitas, Madrid, 1998.
}

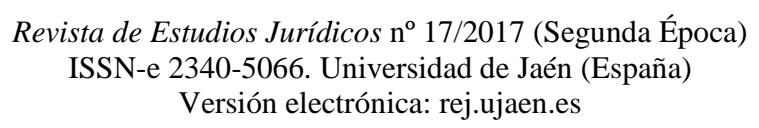


actuaciones excepcionales, reafirmando la norma general de publicidad de los asuntos tratados en la Cámara Baja.

A continuación en los art. 63 y 64 RCD, reguladores del régimen de sesiones de la Cámara nos indica en el primero que las sesiones del Pleno a las que reconoce el carácter público, atendiendo al art. $80 \mathrm{CE}$, excepto en los casos que respecte al "buen decoro" de la Cámara, sus miembros o la suspensión de un Diputado, cuando se debatan propuestas, dictámenes, informes o conclusiones elaboradas en el seno de la Comisión del Estatuto de los Diputados que no afecten a las incompatibilidades parlamentarias y cuando lo acuerde el Pleno por mayoría absoluta de sus miembros, a iniciativa de la Mesa, de dos Grupos Parlamentarios o de la quinta parte de la Cámara. Sobre esto, resulta llamativa la adjetivación del término "decoro" por ser indeterminado, ya que considerando su relación con la suspensión de los Diputados, puede hacer alusión a aquellas cuestiones disciplinarias o de régimen interno, que se vio excluían en la Ley 30/1992 de 26 de noviembre de Régimen Jurídico de las Administraciones Públicas y del Procedimiento Administrativo Común ${ }^{14}$ (LRJPAC) respecto a los archivos sobre implicaciones que tienen respecto a la dignidad y honor, protegidos por los arts. 10 y 18 CE.

Parece ser que se excluyen pareceres sobre prerrogativas, deberes, adquisición, suspensión y pérdida de la condición de Diputado y todos aquellos aspectos que recoge su Estatuto, excepto el régimen de incompatibilidades, el cual no parece ser susceptible de exclusión y deberá ser objeto de publicidad. A continuación, se establece una cláusula abierta en la que parece que cualquier materia podrá ser objeto de secreto, siempre y cuando así lo acuerde el Pleno. Aunque se exige una mayoría contundente para su aprobación, no se explica que con esta cláusula se permita dejar al libre albedrío del propio organismo afectando por una posible solicitud que decida discrecionalmente el secreto de las cuestiones que dilucida.

Por otro lado, el art. 64 que se mencionaba anteriormente, se refiere al régimen de las sesiones aunque en este caso, de aquellas correspondientes a las Comisiones. Aquí parece regir la regla contraria a la publicidad porque de salida establece con carácter general que no serán "públicas”, aunque parece ser que en función del carácter de “especial consideración” que se explicó profesaba el Tribunal Constitucional (TC) "a los medios que garantizaban la comunicación social y a las personas que profesionalmente los sirven”. Con esto, se distinguen entonces diferentes categorías de sesiones ${ }^{15}$ que plantean la duda de en base a qué criterios organismo se determina qué

\footnotetext{
${ }^{14}$ BOE núm. 285, de 27 de noviembre de 1992, derogada junto con la Ley 6/1997, de 14 de abril, de Organización y Funcionamiento de la Administración General del Estado (LOFAGE. BOE núm. 90, de 15 de abril de 1997) y modificadas por la Ley 39/2015, de 1 de octubre, del Procedimiento Administrativo Común de las Administraciones Públicas (BOE 236 de 2 de octubre de 2015) y la Ley 40/2015, de 1 de octubre, de Régimen Jurídico del Sector Público (BOE núm. 236, de 2 de octubre de 2015).

${ }^{15}$ Que se clasifican en públicas (que serían aquellas a las que cualquier ciudadano puede acudir libremente), no públicas (aquellas a las que no puede asistir quien no ostente la condición de Diputado, comisario o periodista acreditado) y secretas (aquellas a las que no puede asistir nadie que no forme parte de la Comisión y entre las que el propio artículo distingue: aquellas cuya condición de "secreta" se acuerde por mayoría absoluta de sus miembros y las sesiones y trabajos de la Comisión del Estatuto ...).
}

\author{
Revista de Estudios Jurídicos nº 17/2017 (Segunda Época) \\ ISSN-e 2340-5066. Universidad de Jaén (España) \\ Versión electrónica: rej.ujaen.es
}


medio está acreditado para asistir a qué sesión igual que destaca la discrecionalidad de la Comisión para determinar el carácter secreto o reservado de sus reuniones.

Por consiguiente, el art. 64.4 RCD dispone además que "Las sesiones de las Comisiones de Investigación... no serán públicas”, con lo que se deja de reiterar la norma establecida en el punto primero del precepto que dispone que las sesiones de las Comisiones serán restringidas, en el sentido de no permitir el acceso a cualquier ciudadano. Reza además que "se ajustarán...las sesiones que tengan por objeto la celebración de comparecencias informativas ante las Comisiones..." por lo que se reitera con el carácter restringido establecido en el epígrafe primero del art. 64, es decir, restringir el acceso a cualquier ciudadano con la excepción de Diputados, miembros de la Comisión y los medios de comunicación social debidamente acreditados. Para estos medios de comunicación se hace una nueva excepción en los casos en que las citadas comparecencias informativas ante dichas comisiones de Investigación sean secretas explicando que "verse sobre materias que hayan sido declaradas reservadas o secretas" o porque "coincidan con actuaciones judiciales...declaradas secretas”.

Siendo estas exclusiones ya conocidas por ser los límites comunes usados en la normativa general en transparencia que regula el acceso y cuyo sentido viene marcado por otras autoridades públicas distintas al propio Congreso como son el Consejo de Ministros en el caso de materias clasificadas o secretas y el Poder Judicial por medio de Jueces y Magistrados para el supuesto de actuaciones judiciales, lo cual resta discrecionalidad al parecer a la decisión de adoptar el carácter secreto de una cuestión. Finalmente, en virtud del art. 96 del Reglamento dispone que "En el Diario de Sesiones se reproducirán íntegramente...todas las intervenciones y acuerdos adoptados...se levantará acta... Los acuerdos adoptados se publicarán en el Diario de Sesiones...” se consagra de nuevo la publicidad y seguridad jurídica tan conexa al principio de transparencia.

Continuando con la exposición del análisis del Legislativo en transparencia, es de necesidad entrar en el régimen jurídico establecido por el Reglamento del Senado de $1994^{16}$ (RS). Su art. 22.3 mantiene el carácter secreto de aquellas reuniones en las que se le va a informar acerca del dictamen emitido por la Comisión de Suplicatorios para los procesos de inculpación de los Senadores.

El art. 26.3 del mismo, reconoce el carácter secreto del Registro de Intereses en lo que respecta a los bienes patrimoniales de los Senadores pero centrándonos en el régimen de sesiones, donde más materia en transparencia y publicidad de los actos a calificar de Buen Gobierno, se encuentra que es bastante común al dispuesto para las sesiones del Congreso. Así pues para las sesiones del Pleno se dispone también como regla general su carácter público, excepto que a petición motivada de la mayoría absoluta de la Cámara o en aquellos casos previstos por el RS en su art. 72. Con esto se reitera al defecto endogámico de dejar en manos del propio organismo al que afectan las reuniones la decisión de su carácter público o secreto. Posteriormente se hace una

\footnotetext{
${ }^{16}$ BOE núm. 114, de 13 de mayo de 1994.
} 
remisión directa al resto del RS para dilucidar cuales son también sesiones reservadas del Pleno.

Por el contrario de los dispuesto para el Congreso, las sesiones de las Comisiones del Senado no son "no públicas", con lo que deja una duda en la razón de hacer en el art. 75 una mención especial a los representantes acreditados de los medios de comunicación social para legitimarlos al acceso a las sesiones en cuestión ya que si las sesiones son públicas, se interpreta que se podrá acceder con independencia del oficio del solicitante.

Finalmente ha de destacarse que también se prevé el carácter secreto de las sesiones de las Comisiones en el art. 75.2 y 75.3 del RS para dos casos tasados como son "aquellos puntos de las mismas que tengan por objeto el estudio de incompatibilidades, suplicatorios y cuestiones personales que afecten a Senadores" y "Las reuniones a puerta cerrada de las Comisiones...”.

Hasta aquí se ha de añadir que el deber de "estricta reserva" respecto de todos los asuntos que Diputados y Senadores conozcan por razón de las Cortes, lo cual supone un serio obstáculo para el acceso, pues si bien el secreto se limita a aquellas sesiones, actas y documentos calificados como tales por Ley, el concepto de reserva aparece vinculado al clásico sigilo funcionarial o prudencia, discreción de todos los asuntos que se conozcan en el cargo, lo cual y a pesar de que el rigor de la reserva es inferior que el secreto, podría extender en la práctica el secretismo a una gran cantidad de asuntos. Es necesario utilizar el criterio dispuesto en el art. 7 del Real Decreto 33/1986, de 10 de enero sobre Régimen Disciplinario de los Funcionarios de la Administración ${ }^{17}$, el cual sanciona con falta grave el "no guardar el debido sigilo respecto de los asuntos que se conozcan por razón de su cargo", en lo que SAINZ MORENO añade que se produzca un perjuicio a particulares por desvelar datos que puedan afectar a su intimidad. ${ }^{18}$

En 1978 ya era una obviedad la importancia de la probidad legislativa, de ahí que exista un procedimiento como el español en la generación de leyes en la que brevemente descrita se inicia primero en la Mesa del Congreso, quien decide si se comienza o no la tramitación de las propuestas a tramitar. Las iniciativas legislativas incluyen exposición de motivos, antecedentes, memoria explicativa y una serie de informes preceptivos que son públicos y van asociados a la Ley: del Consejo General del Poder Judicial (CGPJ), del Consejo de Estado, el Económico y Social, de razón de género, memoria económica o de alguna otra institución del Estado. En cualquier caso, una vez aquí tienen un plazo de 30 días para pronunciarse sobre la posibilidad de continuar con la tramitación donde hay dos tipos de enmiendas aplicables, las parciales o a la totalidad que deben presentarse con la firma de un diputado y el portavoz del grupo parlamentario y con una justificación.

Más tarde la comisión vota el informe que presenta la ponencia y se elabora un dictamen que se envía al Pleno del Congreso o pasa directamente al Senado

\footnotetext{
${ }^{17}$ BOE núm. 15, de 17 de enero de 1986.

18 SAINZ MORENO, F., Secreto y Transparencia, Estudios para reforma de la reforma de la administración pública, INAP. Madrid, 2004, p. 54.
}

\footnotetext{
Revista de Estudios Jurídicos no 17/2017 (Segunda Época) ISSN-e 2340-5066. Universidad de Jaén (España)

Versión electrónica: rej.ujaen.es
} 
dependiendo de si la Mesa del Congreso ha delegado en la Comisión la competencia legislativa plena o no y este es uno de los momentos más conocidos por la opinión pública de todo el proceso, ya que se debaten las enmiendas más llamativas y que tienen un mayor impacto político. Cuando el texto definitivo se publica en el Boletín Oficial de las Cortes Generales ${ }^{19}$ (BOCG), otra puerta abierta al ciudadano, y se envía al Senado, hay dos meses para acabar de tramitar la ley a no ser que deba tramitarse por vía de urgencia, para lo que contarían con 20 días. En el Senado, a su vez, pueden presentarse dos tipos de enmiendas, al texto del articulado o de veto, o sea devolución de la ley al Congreso o propuesta de un texto alternativo para cambiar el espíritu del enfoque y si el Senado no introduce ningún cambio en el texto se envía directamente al Rey para que lo sancione y se publique en el BOE.

Podemos observar que, atendiendo a los Códigos de Conducta de los diferentes partidos políticos ${ }^{20}$ más representativos en España, se trata constantemente que uno de los principios generales sea que aquella persona que desempeñe un cargo o función lo haga ateniéndose a los principios de transparencia. Finalmente dentro de este Poder, el Titulo 3 de la LTBG subraya la diligencia que el Congreso ha de tener en la materia destacando el art. 40 "Relaciones con las Cortes Generales" que "El Consejo de Transparencia ...elevará anualmente a las Cortes Generales una memoria.... El Presidente del Consejo... comparecerá...”.

En última instancia, y con motivo de la LTBG, se añaden nuevas medidas en este sector, como la creación del Portal de Transparencia en cada Cámara ${ }^{21}$ o el cambio de Régimen económico y ayudas de los Diputados ${ }^{22}$ por el que en se suprime el viático de $150 €$ diarios en concepto de viajes de trabajo en el extranjero y $120 €$ en territorio nacional (120.000 €/mes entre ambas Cámaras ${ }^{23}$, $50.000 €$ /año/parlamentario aprox.) en sustitución de un sistema transparente en el que exclusivamente se abonarán los gastos por desplazamiento "efectivamente producidos y debidamente justificados". Por su parte, la Disposición adicional octava de la LTBG, la cual reza que "El Congreso de los Diputados, el Senado y las Asambleas Legislativas autonómicas regularán en sus

\footnotetext{
${ }^{19}$ Disponible en:

http://www.senado.es/web/actividadparlamentaria/publicacionesoficiales/senado/boletinesoficiales/index. html (Consultado el 18/4/17).

${ }^{20}$ PAU I VALL, F., La Transparencia desde el Parlamento. XXI Jornadas de la Asociación Española de Letrados de Parlamentos, Tecnos, Madrid, 2015, p. 132.
}

${ }^{21}$ Portal de Transparencia del Congreso de los Diputados disponible en: http://www.congreso.es/portal/page/portal/Congreso/Congreso/Transparencia Sección de relación con los ciudadanos y de transparencia del Senado disponible en: http://www.senado.es/web/relacionesciudadanos/transparencia/index.html (Consultado el 10/4/17).

${ }^{22}$ Aprobado por unanimidad en reunión de la Mesa del Congreso de los Diputados en acuerdo con la del Senado y presidida por Ana Pastor (PP) el 11/01/2017 y publicado en el Portal de la Transparencia del Congreso el día 27/01/2017. Texto disponible en: http://www.congreso.es/portal/page/portal/Congreso/Congreso/Diputados/RegEcoyProtSoc/regimen_eco nomico_diputados.pdf (Consultado el 19/4/17).

${ }^{23}$ Diario ABC 27/08/2016. 
respectivos reglamentos la aplicación concreta de las disposiciones de esta Ley" determinó que en cada una de las cámaras representativas de la voluntad del pueblo español se aplicaren sus normas al respecto.

Así pues, en el Congreso la regulación aprobada conforme a lo establecido la constituyen las "Normas de la Mesa del Congreso de los Diputados, para la aplicación de las disposiciones de la Ley 19/2013...a la Cámara, en relación con su actividad sujeta a derecho" de 20 de enero de $2015^{24}$ (NTC) y en la Cámara Alta la "Norma reguladora del derecho de acceso a la información pública del Senado" aprobada en su reunión del día 2 de diciembre de $2014^{25}$ y también las "Normas de acceso externo a las unidades documentales del Senado”, aprobadas por la Mesa de la Cámara del día 3 de mayo de $2012^{26}$.

Respecto a las resoluciones finales del Congreso, inmediata casa legislativa, representativa y de control del Gobierno, ha de señalarse su marco legal en el art. $17^{27}$ NCT, la cual se dedica al régimen de impugnaciones con el rubricado "Recurso ante la Mesa del Congreso de los Diputados” de las resoluciones de la Secretaría General que habilita el procedimiento. Ha de señalarse positivo el estipular un silencio administrativo negativo a los 30 días de la solicitud dada la conocida picaresca que en estos casos podría suponer uno positivo.

\section{B) En el Poder Judicial}

El régimen de acceso a la información en el espacio judicial ${ }^{28}$ parte de la orientación del art. 120.1 CE “Las actuaciones judiciales serán públicas...” donde, desde el principio de publicidad de las actuaciones judiciales, autores como FERNANDEZ RAMOS detallan que "referida a la sociedad...no como publicidad para las partes, tiene por finalidad garantizar el control de la generalidad de la Ley y de su fiel aplicación”29. El Poder

\footnotetext{
${ }^{24}$ BOCG, Congreso de los Diputados, Serie D, número 595, de 23 de enero de 2015.

${ }^{25}$ BOCG, Senado, número 451, de 9 de diciembre de 2014.

${ }^{26}$ BOCG, Senado, número 112, de 30 de octubre de 2012.

${ }^{27}$ Artículo que dispone "1. Frente a toda resolución expresa del Secretario General en materia de acceso a la información sobre la actividad del Congreso sujeta a Derecho Administrativo podrá interponerse recurso ante la Mesa del Congreso de los Diputados”.

28 Remarca FERNANDEZ RAMOS que "En general, el término transparencia viene siendo hoy ampliamente utilizado con referencia no sólo a la acción administrativa, sino también a la judicial” FERNÁNDEZ RAMOS, S., El derecho de acceso a los documentos administrativos, Marcial Pons, Madrid, 1997, p. 320.

29 FERNÁNDEZ RAMOS, S., El derecho de acceso a los documentos administrativos, Marcial Pons, Madrid, 1997, p. 313.
} 
Judicial, por sus principios consustanciales, ha sido y es uno de los órganos en que antes $^{30}$ se ha impuesto la voluntad a la hora de aplicar la transparencia con 4 núcleos:

- El Plan de Transparencia Judicial. ${ }^{31}$

- La Carta de Derechos del Ciudadano ante la Administración de Justicia. ${ }^{32}$

- La Comisión de Estadística Judicial.

- El Portal de Transparencia del CGPJ.

El primero consiste en un proyecto destinado a conseguir una mayor transparencia de los procedimientos judiciales, reforzando los principios de independencia, imparcialidad, competencia, accesibilidad, eficacia, duración razonable en las tramitaciones, calidad, previsibilidad, igualdad y responsabilidad. Se trata de garantizar una adecuada correspondencia entre el coste y el rendimiento del servicio público y para ello se sirve de puntos como dotar de medios estadísticos adecuados que permitan obtener datos válidos sobre la actividad judicial y su calidad a la Administración de Justicia o identificar con precisión todas las instalaciones y equipos de trabajo de la Administración de Justicia en el Estado, las CCAA, provincias y partidos judiciales para evaluar su idoneidad en la implantación eficiente de la Oficina Judicial, tanto para los profesionales como para los ciudadanos usuarios del servicio.

En segundo lugar hemos de destacar la transparencia judicial invocada en la Carta, aprobada como Pacto de Estado por el Pleno del Congreso de los Diputados el 22 de abril de 2002, en la que se reclama la aplicación de los principios de transparencia, información y atención adecuada a los usuarios de la Justicia. En su preámbulo se señala que en el siglo XXI la sociedad española demanda con urgencia una Justicia más abierta, que sea capaz de dar servicio a los ciudadanos con mayor agilidad, calidad y eficacia, incorporando para ello métodos de organización e instrumentos procesales más modernos y avanzados. Concretamente en su preámbulo apela a que "Entre las prioridades... la elaboración de una Carta...que atienda a los principios de transparencia”.

\footnotetext{
${ }^{30}$ La propia jurisprudencia anterior a la LTBG ya discutía acerca de la ponderación como los límites expresos o específicos establecidos por los propios preceptos (como el art 37 LRJPAC) como reconocen las SSTC 77/1985, 11/1981, 27/1982, 110/1984 ó 120/1991.

${ }^{31}$ Aprobado por el Consejo de Ministros, en su reunión del día 21 de octubre de 2005, a propuesta del Ministro de Justicia, aprobó mediante Acuerdo el Plan de Transparencia Judicial, conforme a lo previsto por el art. 14 de la Ley 15/2003, de 26 de mayo, reguladora del régimen retributivo de las carreras judicial y fiscal. En virtud de este precepto se anticipa la "planificación, desarrollo y ejecución de las políticas públicas relativas a la Administración de Justicia”. BOE núm. 261, de 1 de noviembre de 2005, pp. 35729 a 35755 (27 págs.)

${ }^{32}$ Disponible en:

https://www.administraciondejusticia.gob.es/paj/PA_WebApp_SGNTJ_NPAJ/descarga/Carta_de_derech os_de_los_ciudadanos.pdf?idFile=0a3af68a-cfe3-4243-83ba-fd4c05610e72 (Consultado el 1/4/17).
}

\author{
Revista de Estudios Jurídicos nº 17/2017 (Segunda Época) \\ ISSN-e 2340-5066. Universidad de Jaén (España) \\ Versión electrónica: rej.ujaen.es
}


En la "Segunda Parte" del texto que constituye la Carta, se explicita insistentemente el "derecho a recibir información transparente sobre el estado, la actividad y los asuntos tramitados y pendientes de todos los órganos jurisdiccionales de España”. Y se añade que "el Ministerio de Justicia y las CCAA con competencias en la materia, así como el Consejo General del Poder Judicial, canalizarán esta información para facilitar su consulta en el marco de un plan de transparencia”.

A continuación, la Comisión Nacional de Estadística Judicial ${ }^{33}$ (CNEJ) se crea como otra herramienta al servicio de la transparencia por medio de la información procesada convirtiéndose en un organismo encargado de aprobar los planes estadísticos, generales y especiales, de la Administración de Justicia, y establecer criterios uniformes y de obligado cumplimiento para todos sobre la obtención, tratamiento informático, transmisión y explotación de los datos estadísticos del sistema judicial español. Las funciones que corresponden a la CNEJ son la inclusión de datos de carácter general y relativo a cada órgano judicial cuya recogida y publicación se considera útil para cumplir con las finalidades y objetivos del Plan de Transparencia.

Finalmente este Poder concluye su aparato en transparencia con un canal, el Portal de Transparencia, denominado "José Luis Terrero Chacón” en honor al mismo, por Acuerdo de la Comisión Permanente de 17 de marzo de 2015, en homenaje al fallecido Secretario General que fue su principal impulsor, pretende facilitar a toda la ciudadanía el acceso a la información del CGPJ, su actividad, la finalidad del empleo de fondos públicos, los criterios y motivos de sus decisiones y los demás temas de interés público con espacios de publicidad sobre bienes, subvenciones, personal, contratación, presupuestos, altos cargos, acuerdos adoptados por el Pleno y de las Comisiones, la agenda de actividad diaria del CGPJ, los convenios de cooperación con otras instituciones, los estudios realizados en diversos temas, las memorias de estado y funcionamiento anuales y los informes sobre anteproyectos de ley y otras disposiciones.

A todo lo comentado hasta el momento es necesario añadir el deber razonable exigido al personal al servicio de la Administración de Justicia de guardar "secreto riguroso de los asuntos que conozcan por razón de su cargo". Por otro lado, atendiendo al acceso a la documentación en manos del Poder Judicial hay que proceder al estudio de , entre otras, la Ley Orgánica del Poder Judicial 6/1985, de 1 de julio ${ }^{34}$ (LOPJ) y el Reglamento $1 / 2005$, de 15 de septiembre de 2005 de aspectos accesorios a las actuaciones judiciales $^{35}$ y sobre todo al art. $120 \mathrm{CE}$ en el que a pesar de reconocer literalmente la "publicidad de las sentencias" y el carácter público de las actuaciones judiciales, se establecen posteriormente unas limitaciones amplias entre las que destaca por su peculiaridad las derivadas del "secreto de sumario" determinado por el juez.

\footnotetext{
33 Respecto a la composición de la CNEJ, ésta estará integrada por el Ministerio de Justicia, una representación de las Comunidades Autónomas (CCAA) con competencias en la materia, el CGPJ Judicial y la Fiscalía General del Estado. La estructura, composición y funciones han sido establecidas reglamentariamente por el Gobierno, mediante real decreto, previo informe del CGPJ, del Fiscal General del Estado, de la Agencia de Protección de Datos y de las CCAA con competencias en la materia.

${ }^{34}$ BOE núm. 157, de 2 de Julio de 1985.

${ }^{35}$ BOE núm. 231, de 27 de septiembre de 2005.
} 
El art. 232 LOPJ establece como regla general el carácter público de las actuaciones judiciales, con dos excepciones: las excepciones que prevean las leyes de procedimiento y aquellas excepcionalmente vengan determinadas por razones de orden público y las de protección de los derechos en el que serán los jueces y tribunales mediante resolución motivada quienes podrán limitar el ámbito de la publicidad y acordar el carácter reservado de una parte o la totalidad de las actuaciones siempre y cuando lo hagan mediante resolución motivada.

En el precepto 233 LOPJ se extiende el secreto a las deliberaciones de los tribunales y al resultado de las votaciones y los arts. 234 y 235 reiteran al establecer excepciones justificadas en la calificación como secretos o reservados de los archivos, acuerdos, registros y libros así como el estado de las actuaciones judiciales y escritos que consten en autos declarados cuando dicha calificación venga establecida por una ley además de los documentos que se determinen.

Por su parte, el art. 266.1 LOPJ reza "el acceso al texto de las sentencias, o a determinados extremos de las mismas, podrá quedar restringido cuando el mismo pudiera afectar al derecho a la intimidad, a los derechos de las personas que requieran un especial deber de tutela o a la garantía del anonimato de las víctimas o perjudicados...". Si al "secreto de sumario" se atiende en materia de acceso en un órgano transparente, se ha de tildar la supresión del principio de publicidad del proceso cuando así lo determine el juez en determinadas circunstancias. La Ley de Enjuiciamiento Civil primitiva desarrollaba razones de "escándalo u ofensa moral” para practicar a puerta cerrada determinadas actuaciones de prueba, así como de "moral y decoro” para la despensa y vista de ciertos negocios.

Con esto, se sobreentiende que atendiendo a lo indeterminado y subjetivo de dichos conceptos se procede a una reforma del régimen de publicidad que trajo la Ley 1/2000, de 7 de enero, de Enjuiciamiento Civil (LEC), en la que los arts. 138.2 y 140.3 LEC precisan por fin las causas de la celebración de las actuaciones a puerta cerrada y del carácter reservado de la totalidad o a parte de los autos y que tasa en la necesidad de "protección de datos...orden público o de la seguridad nacional en una sociedad democrática, o cuando los intereses de los menores o la protección de la vida privada de las partes y de otros derechos y libertades lo exijan...”. Por otro lado, el precepto 141 LEC, limita el acceso a libros, archivos y registros judiciales que tengan carácter reservado a aquellas personas que acrediten un interés legítimo y obtener, a su costa, testimonio o certificación de los extremos que se indiquen. En última instancia, confirma en su art. 197.1, continuando con lo establecido en el art. 233 LOPJ, que la discusión y votación de las resoluciones se verificarán siempre a puerta cerrada.

Si bien es cierto que en el enjuiciamiento en jurisdicciones como la civil, social, laboral y contencioso, administrativa son más aperturistas, es como no podía ser de otra manera la jurisdicción penal aquella en la que más límites se establecen en términos de acceso y publicidad pues en la Ley de Enjuiciamiento Criminal de 14 septiembre de 1882 (LECRIM) solo se contemplaba el juicio oral pero en ningún caso en la fase preparatoria de la instrucción del sumario según lo dispuesto en sus arts. 301 y 322. En el juicio oral, también se podrán celebrar a puerta cerrada los debates por razones de 
“moralidad o de orden público...”, según establece el art. 680 LECRIM. Finalmente el art. 150 LECRIM mantiene igual que ocurre con la analizada LOPJ y la LEC que la discusión y votación de las sentencias se verificará en todos los tribunales a puerta cerrada.

C) En el Poder Ejecutivo

Aquí, epicentro de la tendencia reformista, encontramos los evidentes efectos de las exigencias sociales con una estructura consolidada y por consolidar en la que por ser de sobra conocida, se expondrá sucintamente. Si el Ejecutivo en España está constituido por el Gobierno y la Administración, es de entender que hayan sido las principales protagonistas de la LTBG y su reglamento de desarrollo en proyecto, legislación que, en suma establece un ámbito subjetivo de entes obligados a garantizar una transparencia, dispone los principios que han de regir, los mecanismos de solicitud de información pública y su régimen de impugnaciones así como otros puntos como el Buen Gobierno con sanciones aplicadas a conductas que a esta materia contradigan así como la creación de un órgano independiente ${ }^{36}$ en este campo como es el Consejo de la Transparencia y Buen Gobierno.

Desde el punto de vista administrativo, el derecho de acceso ya no se configura tan solo como un derecho, sino que se compatibiliza con su concepción como un principio para determinar la transparencia, el acceso a la información y el Buen Gobierno en la gestión de recursos tal y como recogía el art. 3.5 LRJPAC, el art. 3.2.g LOFAGE y el Código de Buen Gobierno de los Miembros del Gobierno y Altos Cargos de la Administración General del Estado $^{37}$ al establecer principios de eficacia, claridad, objetividad y transparencia como reglas de funcionamiento de una Administración recogiendo en el ámbito internacional el contenido de la Declaración del Milenio de Naciones Unidas del año $2000^{38}$ y el Libro Blanco de la Gobernanza Europea ${ }^{39}$.

En el nuevo concepto de Administración que propicia la solución a todos los avatares, se introducen principios de actuación o funcionamiento en los que se inspiran los

\footnotetext{
${ }^{36}$ LOZANO MIRALLES citando a SANTAMARÍA PASTOR "no hay nada más peligroso que crear órganos independientes, pues es la mejor manera para asegurar su ineficacia”, LOZANO MIRALLES, J., “Órganos de control externo y Parlamento”, Revista de las Cortes Generales, núm. 40, 1997, p. 173.

${ }^{37}$ Por el Acuerdo del Consejo de Ministros de 18 de febrero de 2005 (BOE núm. 56, de 7 de marzo de 2005) , principio de conducta $3^{\circ}$, principio ético $10^{\circ}$ y principio básico $1^{\circ}$.

38 En su capítulo V dedicado a "Human right, democracy and good governance”, apartado 25 que establece "We resolve therefore: To ensure the freedom ogf the media to perform their essential role and the right of the public to have access to information".

${ }^{39}$ Estableciendo que "Las instituciones deberían trabajar de una forma más abierta. Junto con los Estados miembros, deberían desarrollar una comunicación más activa sobre la labor de la UE y sobre las decisiones que ésta adopta. Deberían asimismo utilizar un lenguaje que resultara accesible para el público. Este aspecto reviste una especial importancia si se quiere fomentar la confianza en unas instituciones de por sí complejas" y para ello mantiene que "La democracia depende de la capacidad de los ciudadanos para participar en el debate público. Para ello, deben tener acceso a una información fiable sobre los asuntos.... En 2001, se han realizado considerables progresos con la aprobación de nuevas formas que permiten a los ciudadanos un mayor acceso a los documentos de la Comunidad”.
} 
operadores privados como la eficacia, la programación y desarrollo de objetivos, la agilidad de los procedimientos y la transparencia dentro de la misma [art. 3.2.g) LOFAGE].

Dicho lo anterior, existe otra faceta que debería abarcar este estudio desde la concepción citada del derecho de acceso y esta no es otra que la representada por las solicitudes de los ciudadanos a otras Administraciones desde el punto de vista territorial como son la Autonómica y la Local como a otros poderes que no son la Administración. Siguiendo una concepción sueca ${ }^{40}$ del derecho de acceso a la información, ha de interpretarse de manera amplia e incluyente para abarcar toda la información existente susceptible de ser solicitada. La doctrina española (POMED, MESTRE y otras autores recomendados) determinan que el derecho que nos ocupa ha de ser extendido a cualquier persona o entidad que atienda a funciones públicas en sentido amplio, o sea, incluyendo servicios públicos o de interés general. Compartiendo plenamente esta postura, habrá que afirmar que son también sujetos pasivos del derecho de acceso los organismos públicos comunes como el resto de corporaciones administrativas ya sean colegios profesionales, cámaras de comercio, industria y navegación, etc.

A nivel administrativo, se ha de citar en este aspecto que la normativa aplicable tanto a nivel autonómico como local puede diferir del establecido por la normativa estatal, pero en cualquier caso deberá respetar los mínimos establecidos por la CE. En el ámbito autonómico se hace palpable desde el respeto que la normativa autonómica en la materia deberá guardar respecto a los derechos fundamentales y la normativa estatal que afecte al derecho de acceso y que se corresponda con la competencia exclusiva del Estado sobre la misma como en materia de justicia, seguridad, defensa, etc.

Tomando del Estatuto Básico del Empleado Público aprobado en la Ley 7/2007, de 12 de abril ${ }^{41}$ (EBEP) los aspectos de transparencia y acceso a la información que vinculaba a los funcionarios autonómicos podríamos citar en los arts. 52, 53.12 y 54.4 EBEP donde se determinan los deberes de confidencialidad, secreto de materias clasificadas o prohibidas, discrecionalidad de actuación por razón del cargo sin que los funcionarios puedan usar la información en beneficio propio o de terceros o en perjuicio de interés público, el deber de informar a los ciudadanos sobre aquellas materias o asuntos que tengan derecho a conocer, y facilitarán el ejercicio de sus derechos y el cumplimiento de sus obligaciones.

Dicho lo cual, atendiendo a lo dispuesto en el art. 148.1.18 CE, se sobreentiende que las autonomías podrán regular el desarrollo del régimen jurídico de acceso contemplado en el art. 37 LRJPAC con sus peculiaridades y actualizaciones por cuanto que se establece que las bases del régimen jurídico de las Administraciones y las reglas del procedimiento que integran el concepto de procedimiento administrativo común.

\footnotetext{
40 PALOMARES HERRERA, M., "Comparative study on transparency and right of access in the international sphere and its influence in Spain”. Ius Humani Law Journal, v. 6, 2017, p. 125.

${ }^{41}$ BOE núm. 89 de 13 de Abril de 2007. [Reformado por el Real Decreto Legislativo 5/2015, de 30 de octubre, por el que se aprueba el texto refundido de la Ley del Estatuto Básico del Empleado Público. (BOE núm. 261, de 31 de octubre de 2015)].
}

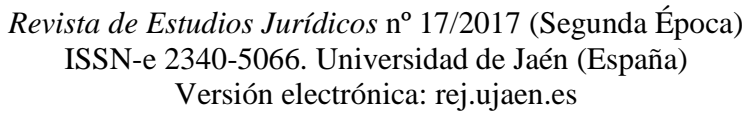


A título enunciativo en la transparencia en las Entidades Locales, se hace necesario acudir a la legislación representada fundamentalmente por la Ley 7/1985 Reguladora de las Bases de Régimen Local ${ }^{42}$ (LBRL) y al Real Decreto 2568/1986 de Reglamento de Organización, Funcionamiento y Régimen Jurídico de las Entidades Locales ${ }^{43}$ (ROF). ${ }^{44}$

En la primera, el art. 69 comienza exponiendo un principio general sobre la facilitación más amplia de información por parte de las Corporaciones sobre la actividad que desempeñan especialmente en las sesiones de las mismas. De éstas, el art. 70 LBRL y el art. 227 ROF relatan que pueden ser secretos los debates y las votaciones de las materias que puedan afectar al derecho fundamental de los ciudadanos a que se refiere el art. 18.1 CE, cuando se acuerde por mayoría absoluta y que no serán públicas las sesiones de la Junta de Gobierno ni las sesiones de la Comisión de Gobierno ni de las Comisiones informativas, sin embargo ha de tenerse en cuenta que a las sesiones de estas podrá convocarse, a los meros efectos de escuchar su parecer o recibir su informe a un tema específico, a representantes de las asociaciones o entidades a que se refiere el art. 72 LBRL. También pueden ser públicas las sesiones de los órganos complementarios que puedan ser establecidos por el reglamento orgánico municipal, en los términos que prevean la legislación y las reglamentaciones o acuerdos plenarios por los que se rijan.

Atendiendo a los arts. 70.2 LBRL y al art. 196 ROF, los acuerdos que adopten las corporaciones locales se publicarán o se notificarán en la forma prevista. Las ordenanzas, incluidos el articulado de las normas de los planes urbanísticos, así como los acuerdos respectivos a éstos de cuya aprobación definitiva sea competencia de las Entidades Locales, se publicarán en el Boletín Oficial de la Provincia y no entrarán en vigor hasta que se haya publicado completamente su texto y haya transcurrido el plazo previsto en el art. 65 LBRL (un mes) salvo los presupuestos y ordenanzas fiscales que se publicarán y entraran en vigor en términos establecidos en la Ley 39/1988, de 28 de diciembre reguladora de las Haciendas Locales ${ }^{45}$.

La Administración con competencia urbanística deberán tener a su vez, a disposición de los ciudadanos que lo soliciten, copias del planeamiento vigente en su ámbito territorial. Aquellos acuerdos que adopten el Pleno y la Comisión de Gobierno, cuando tengan carácter decisorio se publicarán y notificarán en la forma prevista por la Ley. Iguales requisitos serán de aplicación a las resoluciones del Presidente de la Corporación y miembros que ostenten delegación. De la misma manera, la STS de 1 de diciembre de

\footnotetext{
${ }^{42}$ BOE núm. 80, de 3 de abril de 1985.

${ }^{43}$ BOE núm. 305, de 22 de diciembre de 1986.

44 En este punto advertir, por no ser objeto de la presente, la existencia de duplicidades locales en la materia que la Comisión para la Reforma de las Administraciones Públicas (creadas por Acuerdo del Consejo de Ministros del 26/10/2012) tiene por misión identificar y eliminar. Conviene apuntar al respecto la reflexión de SALVADOR CRESPO acerca de las intenciones legislativas de racionalización y sostenibilidad de la Administración local la cual "se ha focalizado en la necesidad de revisar el mapa municipal, de reformar las competencias locales para evitar duplicidades", duplicidades que, como señalábamos, también alcanzan en ocasiones a la rendición de cuentas, transparencia y acceso a la información. SALVADOR CRESPO, M., "Retos y oportunidades para el Gobierno local en tiempos de crisis”. Revista Cuadernos Manuel Giménez Abad, no 4, 2012, p. 55.
}

${ }^{45}$ BOE núm. 59, de 9 de marzo de 2004. 
1987 ha reconocido, al igual que vimos que se hacía en materia ambiental, una especie de acción pública para exigir la publicidad de los acuerdos de las Corporaciones Locales basada en el derecho de participación ciudadana en los asuntos públicos.

Respecto al derecho de acceso a los documentos locales como por ejemplo los expedientes, actos o acuerdos, el art. 18.1 LBRL en su punto e) comienza estableciendo como derecho y deber de los vecinos el ser informado, previa petición razonada, y dirigir solicitudes a la Administración municipal en relación a todos los expedientes y documentación municipal, de acuerdo con lo previsto en el art. 105 CE. El acceso derecho de acceso a la información pública local puede hacer bien por medio de la documentación de los archivos y registros generales de los arts. 151, 179 y 198 ROF, el padrón municipal del art. 17 LBRL, el registro de intereses del art. 32 ROF y la obtención de copias, certificaciones y aclaraciones de los acuerdos de las Corporaciones y sus antecedentes como establecen los arts. 70.3 LBRL y 207 ROF, y finalmente las solicitudes de información sobre asociaciones de vecinos del art. 234 ROF. Si a limitaciones ha de referirse en este momento el tema, ha de volverse en este ámbito al art. 105.b) CE, como el respeto de los derechos fundamentales reconocidos en la CE $\mathrm{u}$ otras como por ejemplo el entorpecimiento de las tareas de los servicios municipales.

En último lugar debe hacerse mención del papel de los Planes de Gobierno Abierto ${ }^{46}$ que España desarrolla por su pertenencia a la Alianza para el Gobierno Abierto. ${ }^{47}$ Estos planes constituyen una declaración de objetivos para un lapso de tiempo siendo de 2012 a 2014 el primero, 2014 a 2016 el segundo y 2017 a 2019 el actual. ${ }^{48}$ Una vez cumplido el trienio se evalúa la consecución de objetivos y el cumplimiento del plan por el Ministerio de la Presidencia y por una evaluadora externa compuesta por un grupo de investigación independiente especializado en la materia y la propia Alianza. El presente, III Plan, está aún en fase de desarrollo si bien del anterior destaca el cumplimiento del $80 \%$ de los compromisos el informe de autoevaluación ${ }^{49}$. Aunque es una medida éticamente destacable, quedarán los planes a nivel de declaración de intenciones mientras no posea algún elemento de ejecutividad y se elimine la autoevaluación.

\section{Otros entes autónomos del Estado}

A continuación, por su carácter autónomo y por no vinculación inmediata a un Poder concreto, a pesar de su viso judicial, se mencionará lo propio acerca del TC, el Tribunal Europeo de Derechos Humanos (TEDH) y el Defensor del Pueblo (DP). Para el primero rige un sistema muy parecido al expuesto para el poder judicial al establecer el art. 80

\footnotetext{
${ }^{46}$ Disponible en:

http://transparencia.gob.es/transparencia/transparencia_Home/index/GobiernoParticipacion/Gobiernoabierto/I-PlanAccionGA.html (consultado el 17/5/2017).

47 Disponible la sede virtual de la entidad en: https://www.opengovpartnership.org/ (consultado el 17/05/2017).

${ }^{48}$ La sede virtual señalada dispone que "La situación política de gobierno en funciones, desde diciembre de 2015 hasta noviembre 2016 (constitución del nuevo Gobierno), impulsó a España a solicitar a la OGP pasar a formar parte de los países que desarrollan sus planes de acción en los ciclos bienales de años impares”

${ }^{49}$ Disponible en: http://transparencia.gob.es/transparencia/dam/jcr:38c9e35d-0095-44a0-b07be2815c1f35e1/gobierno-abierto-OGP-autoevaluacion-II-plan-nacional.pdf $\quad$ p.27 (consultado el 17/5/2017).
} 
de la Ley orgánica 2/1979, de 2 de octubre, del Tribunal Constitucional ${ }^{50}$ (LOTC) que "se aplicarán, con carácter supletorio de la presente Ley, los preceptos de la Ley orgánica del Poder Judicial y de la Ley de Enjuiciamiento Civil, en materia de...publicidad y forma de los actos, comunicaciones y actos de auxilio jurisdiccional...”.

Igualmente el art. 82.2 LOTC reconoce que el TC podrá disponer las medidas necesarias para preservar el secreto que legalmente afecte a determinada documentación y el que por decisión motivada acuerde para determinadas actuaciones. En cuanto a las sentencias, según el art. 86.3 LOTC, su publicidad podrá verse afectada por las medidas necesarias para la protección de derechos contemplados en el art. 18.4 CE. A ello hay que añadir de nuevo el deber del personal al servicio del TC de guardar secreto o reserva sobre aquello que conozca por razón de su cargo.

El TC mediante recurso de amparo por violación de derechos fundamentales, en el caso actual, desde la perspectiva del art. $20 \mathrm{CE}$ u otros con el que el derecho de acceso a archivos o registros pudiera o pudiese tener conexión instrumental directa ya que el art. 105. b) CE no se puede considerar desgraciadamente y de forma individualizada como un derecho fundamental autónomo como describe la Sentencia del TC (STC) 161/1998, de 20 de septiembre al establecer de forma taxativa que las normas y principios del art.105. b) CE "son inadecuadas para fundamentar una petición de amparo en cuanto en ninguno de ellos se reconoce derechos fundamentales y libertades públicas de los incluidos como amparables en el art. 52.2 CE”.

El TEDH, en última instancia, entrará en escena una vez haya sido desestimado el recurso de amparo en el TC aludiendo a la posible violación del art. $10^{51}$ del Convenio Europeo de Derechos Humanos aludiendo a la libertad de expresión y de acceso a la información. Solo en los casos en los que la solicitud reúna los requisitos para en ulteriores instancias poder ejercer una defensa efectiva, se podría considerar que estamos ejerciendo el mismo, y por tanto, se darían las circunstancias aludidas por la jurisprudencia del TEDH para ser objeto del respectivo recurso.

En cuanto al DP, es destacable por algunos autores que podría considerarse esta figura como una autoridad independiente que conozca de los conflictos surgidos en torno al acceso a la información aprovechando la ventaja amplia que significa el privilegio con el que cuenta el DP para acceder a la documentación administrativa y que permite a esta institución solicitar a los tres Poderes los archivos, expedientes, en todo caso informaciones necesarios para el desarrollo de su función, incluidos aquellos clasificados como secretos, tal y como reconoce el art. 22.1 de su propia Ley Orgánica 3/1981 de 6 de abrill ${ }^{52}$ (LODP). No obstante ha de tenerse en cuenta la temida opción de

\footnotetext{
${ }^{50}$ BOE núm. 239, de 5 de octubre de 1979.

51 Art. 10 de la Carta Europea de Derechos Humanos (CEDH) “ 1 . Toda persona tiene derecho a la libertad de expresión. Este derecho comprende la libertad de opinión y la libertad de recibir o de comunicar informaciones o ideas sin que pueda haber injerencia de autoridades públicas y sin consideración de fronteras... 2. El ejercicio de estas libertades, que entrañan deberes y responsabilidades, podrá ser sometido a ciertas formalidades...”.

${ }^{52}$ BOE núm. 109, de 7 de mayo de 1981.
}

\author{
Revista de Estudios Jurídicos n 17/2017 (Segunda Época) \\ ISSN-e 2340-5066. Universidad de Jaén (España) \\ Versión electrónica: rej.ujaen.es
}


que la vía del DP se convierta en una vía opcional, mejorada, alternativa a modo de atajo a la jurisdicción contencioso-administrativa tanto por su gratuidad por no exigirse postulación de abogado y procurador así como la comodidad que ofrecen unos plazos más amplios (un año desde el hecho) y la superior velocidad con la que resuelve, pues no ha de olvidarse que la Administración ha de contestar al DP en 15 días.

En forma de reclamación o queja se obliga a la Administración a que actúe revisando el expediente o al menos la resolución, en este caso, la de permitir el acceso o denegarlo a una información solicitada. En el improbable caso de que existan indeterminaciones, errores o anomalías en la resolución o en el procedimiento, la Administración Pública ha de responder al DP reconociendo sus errores o bien subsanándolos, lo que supondría la modificación de la resolución. Es evidente que en el supuesto en que se declinase por la primera salida o bien en aquellos casos en que la Administración no reconociese simplemente error alguno, el DP tiene la facultad de presentar una sugerencia que no tendría la misma fuerza que una resolución judicial y que solo puede terminar en una puesta al tanto de la cuestión al Ministro o máxima autoridad administrativa correspondiente o informe al Congreso.

De igual forma se ha de resaltar que LODP prevé el carácter de absoluta reserva de las investigaciones que éste realice así como de los trámites procedimentales, debiendo disponer las medidas especiales de protección respecto a los documentos calificados de “clasificados” o "secretos” según su art. 22.2 LODP. Finalmente el art. 16 LODP menciona el secreto de las conversaciones entre el DP y sus delegados con cualquier otro individuo internado en un centro de detención, internamiento o custodia con lo que se vuelve a contemplar en su reglamento, el deber del personal de este órgano de guardar estricta reserva en relación con los asuntos que ante el mismo se tramiten. Esta es, finalmente y en conclusión, la pesada estructura de publicidad ${ }^{53}$ y transparencia de Estado que sustenta un tercio del Estado de la transparencia.

\title{
3. Breve referencia a la transparencia en las CCAA
}

Como no podía ser de otra manera para una Ley del tipo de la LTBG, da un alcance directo a las CC.AA. Este alcance, desprendido de los arts. 2.1, 5.2, 12.1 y 22.4 LTBG, sirve para advertir sin demasiada dificultad su aplicación directa a las CCAA. ${ }^{54}$ Aludiendo brevemente a las regulaciones en acceso a la información y transparencia autonómica y localmente, ha de especificarse que respecto a la forma de abordar las CCAA sus premisas en transparencia han sido distintas al ser elaboradas por unas antes de la LTBG y otras después en virtud de la puesta en vigor de la norma en base a su disposición final novena "Los órganos de las Comunidades Autónomas y Entidades Locales dispondrán de un plazo máximo de dos años para adaptarse a las obligaciones contenidas en esta Ley”.

\footnotetext{
53 Según la STC 96/1987, de 10 de junio de 1987 la publicidad “ocupa una posición institucional en el Estado de Derecho que la convierte en una de las condiciones de la legitimidad constitucional de la administración de justicia”.
}

54 RIDAO MARTÍN, J., "La transparència i el dret d’accés a la informació pública en la llei catalana 19/2014: Reflexions entorn al seu abast i al marc competencial en què s’insereix”, Revista para el Análisis del Derecho, núm. 4, 2015, p. 9.

\author{
Revista de Estudios Jurídicos nº 17/2017 (Segunda Época) \\ ISSN-e 2340-5066. Universidad de Jaén (España) \\ Versión electrónica: rej.ujaen.es
}


Si atendemos legislativamente a este más que amplio lapso de tiempo de dos años y aludimos a la esencialidad y a las imprescindibles especificaciones de calado que posee la LTBG, ofrece a las CCAA un campo de trabajo abierto a la norma para profundizar en cuestiones como sus propios consejos, plazos o procedimientos. En este sentido RIDAO MARTÍN destaca que "es obvio que queda un margen implícito suficientemente amplio para que el legislador autonómico prevea regímenes propios y más amplios que los previstos en la legislación estatal”. ${ }^{5}$

Este retraso en la normativa ordinaria estatal sobre transparencia y acceso a la información ha hecho que diversas CCAA hayan tomado la delantera aprobando sus propias normas. El resultado de la publicación de normativas en la misma materia sobre los mismos contenidos en cada región, provincia y municipio ha supuesto una verdadera transversalización que ha difundido los principios y bondades de la norma, pero en la forma no puede negarse las excesivas duplicidades. Que un acto como el de solicitud de información pueda ejercerse por tres vías distintas, existan órganos con mismas competencias, con los cuerpos y financiación que ello supone, deriva en una red legislativa sobredimensionada en menos de 10 años.

No obstante, ha de ofrecerse espacio al desarrollo de las mismas para valorar sus resultados. Esta valiente disposición en afrontar una materia en la escala autonómica sin haber existido aún el debate propio en las Cortes siembra un antecedente de peso de donde se recogieron experiencias, todas ellas como avanzadilla de la LTBG. El caso de las Islas Baleares (Ley 4/2011 de la buena administración y del buen gobierno de las Illes Balears), Navarra (Ley 11/2012 de la Transparencia y del Gobierno Abierto), Extremadura (Ley 4/2013 de Gobierno Abierto de Extremadura) y Galicia, aunque también posee actualizaciones al respecto tras la LTBG.

De esta última, podemos decir que fue la más antigua en abordar un concepto autonómico de "información pública” más abierto que el constitucional y que aunque no utiliza la expresión "publicidad activa” posee formas que la asimilan ${ }^{56}$. Extremadura ${ }^{57}$ es la más similar a la LTBG quizás por ser de redactadas casi a la par, de las leyes, sin embargo, normas como la de Baleares se distinguen claramente de la estatal al diferenciar entre el ámbito administrativo (publicación de la su actividad, especialmente la contractual) y el ámbito político (donde entraría la prevención de conflictos de

55 RIDAO MARTÍN, J., “La transparència i el dret d’accés a la informació pública en la llei catalana 19/2014: Reflexions entorn al seu abast i al marc competencial en què s’insereix”, Revista para el Análisis del Derecho, núm. 4, 2015, p. 32.

56 “...somete a publicidad la programación anual y plurianual, contratos públicos, convenios de colaboración, concesiones de servicios y actividades de fomento” La normativa autonómica en materia de derecho de acceso a la información pública, Colección Estudios y Documentos de INAP, Madrid, 2016, p. 14.

57 “En este sentido cabe mencionar la legislación de la Comunidad Autónoma de Extremadura como consecuencia de la implantación del buen gobierno y que ha tenido su plasmación en la Ley 1/2014, de 18 de febrero, de regulación del estatuto de los cargos públicos del Gobierno y la Administración de la Comunidad Autónoma de Extremadura y en el Decreto 3/2015, de 27 de enero, por el que se aprueba el reglamento de desarrollo de la misma”. La normativa autonómica en materia de derecho de acceso a la información pública, Colección Estudios y Documentos de INAP, Madrid, 2016, p. 154. 
interés registro de actividades y otras medidas de buen gobierno). De las leyes Balear y de la de Gallega comentar que recogen premisas y reminiscencias de la extinta LRJPAC pero no recogen un procedimiento de derecho de acceso a la información propiamente dicho, como sí hace la ley navarra ${ }^{58}$ a pesar de que su procedimiento de revisión de resoluciones en materia de derecho de acceso no cuenta con un órgano como el Consejo de la Transparencia y Buen Gobierno (CTBG) y se basa en el sistema de recursos establecido en la LRJPAC.

Ya, después del año 13, con la entrada en vigor de la LTBG, se publicó el resto de normas autonómicas de acceso y transparencia en Andalucía (Ley 1/2014, de 24 de junio, de Transparencia Pública), La Rioja (Ley 3/2014, de 11 de septiembre, de Transparencia y Buen Gobierno), Aragón (Ley 8/2015, de 25 de marzo, de Transparencia de la Actividad Pública y Participación Ciudadana), Comunidad Valenciana (Ley 2/2015, de 2 de abril, de Transparencia, Buen Gobierno y Participación Ciudadana ), Canarias (Ley 12/2014, de 26 de diciembre, de transparencia y de acceso a la información pública ), Murcia (Ley 7/2016, de 18 de mayo, de Reforma de la Ley 12/2014, de 16 de diciembre, de Transparencia y Participación Ciudadana), Castilla y León (Ley 3/2015, de 4 de marzo, de Transparencia y Participación) Cataluña (Ley 19/2014, de 29 de diciembre, de transparencia, acceso a la información pública y buen gobierno) y Galicia (Ley 1/2016, de 18 de enero, de transparencia y buen gobierno) con excepciones como Madrid que deposita las competencias de transparencia y acceso al Consejo Consultivo Autonómico ${ }^{59}$ o Cantabria, Asturias y Castilla La Mancha que las tienen anteproyectadas.

En el caso de Andalucía, se constituyó un órgano para dos cuestiones, tanto la garantía de la intimidad como la del acceso a la información en el bautizado Consejo de Transparencia y Protección de Datos, autoridad independiente de control en materia de protección de datos además de transparencia en cuyo art. 47 se establece que la persona titular de la Dirección del Consejo será nombrada por el consejo de Gobierno previa designación del Parlamento de Andalucía por mayoría absoluta, designación que se producía con fecha de 22 de diciembre de 2015, en el transcurso de la sesión celebrada los días 22 y 23 de diciembre. Posee además una dirección con varios elementos de apoyo como la secretaría y tres áreas sin contar con una comisión amplia. Distinta conformación posee Gobierno Abierto de Navarra por ejemplo. El Consejo de Transparencia navarro, conforme a lo dispuesto en el art. 73 de la Ley Foral, establece

\footnotetext{
${ }^{58}$ Se dice que es la norma que más y mejor desarrolla la LTBG en La normativa autonómica en materia de derecho de acceso a la información pública, Colección Estudios y Documentos de INAP, Madrid, 2016, p. 163.

59 La sede virtual del Consejo describe esta labor en su memoria al afirmar "Son de destacar las modificaciones establecidas en su norma constitutiva, por la Ley 4/2014 de Medidas Fiscales y Administrativas, añadiéndole un Titulo IV en que se configura como Consejo de la Transparencia y Buen Gobierno. A partir de ahora, el Consejo entenderá de las reclamaciones que se puedan plantear contra las resoluciones expresas o presuntas sobre acceso a la información pública”. Disponible en: http://www.madrid.org/ccmadrid/index.php?option=com_content\&view=article\&id=54:tabla-dememorias\&catid=19:publicaciones\&Itemid=40 (consultado el 2/6/2016).
} 
cual es la composición del mismo, la cual reside en menos miembros, elegidos democráticamente y para cuatro años.

Destaca de la norma andaluza 1/2004 su Título V (arts. 50 a 58), en virtud del cual se dispone como "muy grave" la infracción consistente en el "incumplimiento de las obligaciones de publicidad activa previstas...cuando se haya desatendido el requerimiento expreso del Consejo de Transparencia y Protección de Datos de Andalucía...La denegación arbitraria del derecho de acceso a la información pública...El incumplimiento de las resoluciones dictadas en materia de acceso por el Consejo de Transparencia y Protección de Datos de Andalucía en las reclamaciones que se le hayan presentado". Además su potestad sancionadora se comparte entre la Administración, la Consejería de la Junta de Andalucía e incluso la entidad local correspondiente las cuales pueden también imponer multas como sanción de hasta 400.000 euros.

Así, podemos decir finalmente que la situación de la transparencia en España, comenta RUIZ-RICO RUIZ, responde a la inacción del legislador estatal y a la jurisprudencia constitucional, con efectos dilatorios de su regulación ${ }^{60}$, no obstante, la progresiva consolidación de instrumentos autonómicos orientados a la información pública y la participación ciudadana tiende a impulsar la calidad democrática. Además de toda la regulación dispuesta por el legislador autonómico, existen otras iniciativas que se encuentran en tramitación y están actualmente anunciadas. Queda en el margen de actuación de las actuaciones CCAA por tanto decidir la amplitud de sus leyes y hacerlo de forma realista y coherente en el marco estatal ${ }^{61}$.

\section{III.- ANCLAJE Y TENDENCIA DEL DERECHO DE ACCESO A LA INFORMACIÓN}

Más allá de la exégesis de transparencia de Estado, expuesta en defensa del acceso como derecho fundamental, este epígrafe desgranará en primer lugar una aproximación, un análisis y las expectativas de la transparencia y el acceso a la información desde una perspectiva teórica $^{62}$.

\footnotetext{
${ }^{60}$ RUIZ-RICO RUIZ, C., “Transparencia y participación en el Derecho Autonómico: un análisis constitucional”, Revista Internacional de Doctrina y Jurisprudencia, 2004, Vol. 6, nº 1, p. 1.

${ }^{61}$ GUICHOT, E., Transparencia y Buen Gobierno, Estudio y Ley, Aranzadi. Cizur Menor, 2014, p. 13.

62 En la teoría de los derechos fundamentales ALEXY apunta a la distinción de tres dimensiones de la dogmática jurídica en el estudio, entendiendo esta como intento de dar respuesta a problemas (p.32). Extrayendo durante el estudio elementos de normas positivas y de doctrina, las dimensiones del estudio serían la analítica ("Análisis de los conceptos fundamentales hasta la investigación de la estructura jurídica y de la fundamentación sobre la base de los derechos fundamentales”) la dimensión empírica (“en donde quien quiera formular enunciados empíricos tiene que interpretarlos a la luz de suposiciones que son las que hacen que estos hechos sean fuentes de derecho") y la dimensión normativa (“orientación y crítica de la praxis jurídica”). ALEXY, R., Teoría de los derechos fundamentales, Centro de Estudios Constitucionales, Madrid, 1993, pp. 28-29.
} 
En primer lugar, la defensa iusfundamentalista, desde la dogmática jurídica de ALEXY se define como aquella que tiene como misión el "intento de dar una respuesta racionalmente fundamentada a cuestiones valorativas que han quedado pendientes de solución respecto a un material”63. Respecto al segundo elemento, el iusfundamentalismo, por la concepción que ofrece CARBONELL a lo largo de toda su obra ha de llegarse a una conclusión de la que hay que iniciar esta sección. Esta es que los derechos fundamentales son considerados como tales en la medida en que constituyen instrumentos de protección a los intereses más importantes del ser humano. Esto es así puesto que tutela los bienes indispensables para poder desarrollar cualquier plan de vida de la manera más digna posible. En el caso que nos ocupa se defiende la idea del derecho de acceso como objeto de protección para la tutela de un bien tan necesario en nuestros días como lo es la información pública (datos, documentos, expedientes, declaraciones, partidas, archivos, registros) en posesión de la Administración, sin los cuales no puede desarrollarse un plan de vida íntegro dada la sistematización de las TIC's en el Estado.

La defensa de la naturaleza de un derecho de acceso como derecho fundamental se hace desde dos posiciones, la primera desde la vinculación a otros derechos fundamentales existentes en la CE como hemos desarrollado en el anterior epígrafe y la segunda por sí mismo como derecho autónomo ${ }^{64}$. En este apartado se pretenden consolidar posiciones, abrir nuevos argumentos y plantear que nuestro modelo permite la creación de derechos fundamentales sin tener que aludir a la interpretación de otros preceptos. Muchos negacionistas de esta posibilidad se han escudado en que el art. 10.2 CE no permite crear nuevos derechos fundamentales, es cierto, pero sí se permite interpretarlos, por lo que en la posición por conexión se puede y debe interpretar cuál es el alcance del art. 20 CE respecto al acceso, no de crear un derecho de la nada conectándolo con el art. 23 CE y la participación ciudadana, que también.

El tratamiento del derecho de acceso como derecho fundamental, a pesar de la discusión y según MENDEL, ofrece la conformidad y el beneplácito de los grandes de la doctrina a favor de su naturaleza fundamental ${ }^{65}$. Por esta razón se podría haber realizado mediante Ley orgánica de la misma forma que se hizo con el derecho fundamental a la Protección de los datos de Carácter personal que tampoco aparece explícitamente entre los derechos fundamentales y se aprobó a partir del párrafo $4^{\circ}$ del art. $18 \mathrm{CE}$ con lo que a los negacionistas del iusfundamentalismo se les refuta la imposibilidad al haberse visto que sí que es posible. La evolución social exige que las respuestas jurídicas se

63 ALEXY, R., Teoría de los derechos fundamentales, Centro de Estudios Constitucionales, Madrid, 1993, p. 32.

\footnotetext{
64 "La constitucionalización del derecho de acceso a los archivos y registros administrativos supone, y en primer lugar, una especificación para un ámbito funcional concreto del derecho a la información, que recoge con carácter general el art. 20.1.d) CE" .POMED SÁNCHEZ, L., "El derecho de acceso de los ciudadanos a los archivos y registros administrativos”, INAP, Madrid, 1989, p. 110.
}

65 MENDEL, T. "La libertad de información: derecho humano protegido internacionalmente”, Revista Derecho Comparado de la Información, núm. 1, 2003, pp. 43 y ss.

\author{
Revista de Estudios Jurídicos n ${ }^{\circ}$ 17/2017 (Segunda Época) \\ ISSN-e 2340-5066. Universidad de Jaén (España) \\ Versión electrónica: rej.ujaen.es
}


adapten a las necesidades de una sociedad en constante cambio por lo que la legislación puede dar lugar a la aparición de un nuevo derecho fundamental igual que existe una enorme distancia entre los estándares internacionales de transparencia y el derecho de acceso a la información pública que desarrolla la LTBG.

La opción elegida por el legislador no sigue a la tendencia mayoritaria y de actualidad de la doctrina española y difiere de la orientación que las instituciones internacionales atribuyen a la transparencia. En el ámbito europeo, existe un proceso de reconocimiento del derecho de acceso a la información y transparencia como derecho fundamental. La evolución del derecho de acceso en la UE se caracterizó por un inicio tímido de cara a la transparencia y acceso a la información. Tras numerosas regulaciones, en el año 2007 con el Tratado de Lisboa continuó el reconocimiento del derecho de acceso a la información pública y se le otorga fuerza jurídica a la Carta de Derechos Fundamentales de la UE (CDFUE) ${ }^{66}$. Durante todo este proceso, los sujetos obligados a hacer pública la información y a dar trámite a las solicitudes de acceso que recibieran se fue incrementando notablemente, pasando de ser una política de buen gobierno a un derecho constitucional comunitario sobre el acceso a la información.

Así, la Carta de los Derechos fundamentales de la UE establece en el art. 42 de la misma, contenido en el Título V “Ciudadanía”, que: “Todo ciudadano de la Unión y toda persona física o jurídica que resida o tenga su domicilio social en un Estado miembro tiene derecho a acceder a los documentos de las instituciones, órganos y organismos de la Unión, cualquiera que sea su soporte”. De igual modo, el acceso a la información pública se presenta como parte integrante de la libertad de información del art. 10 del Convenio Europeo de Derechos Humanos en los últimos años, de modo que sería contenido del art. 20.1 d) CE. En este sentido, el iusfundamentalista SÁNCHEZ DE DIEGO dedica parte de una de sus obras ${ }^{67}$ a analizar y explicar que tanto TEDH, el Comité de Derechos Humanos de la Naciones Unidas, la Organización para la Seguridad y la Cooperación de Europa y la UE mantienen el carácter fundamental del derecho de acceso a la información pública, mientras que en nuestra ley solo es un derecho administrativo. Sostiene que la LTBG no reúne los requisitos mínimos para adaptarse a las leyes de transparencia de países de nuestro entorno, ni a la normativa internacional a la que España aspira cumplir pues tanto en su alcance teórico como en su ejercicio práctico, el derecho de acceso a la información pública se consagra como un pilar imprescindible para el funcionamiento democrático debido al requisito de que los actos de gobierno han de ser públicos en cualquier Estado de Derecho.

\footnotetext{
${ }^{66}$ Diario Oficial de la Unión Europea (DOUE) núm. 83, de 30 de marzo de 2010.

67 SÁNCHEZ DE DIEGO FERNÁNDEZ DE LA RIVA, M., Participación, representación y Democracia, XII Congreso de Constitucionalistas de España, Universidad de Salamanca, 2014.
} 


\section{Anclaje $e^{68}$ constitucional del derecho de acceso a la información}

Antes de entrar en materia es de necesidad proponer brevemente los posibles anclajes que nuestro texto fundamental ofrece al derecho de acceso a la información pública. Los únicos artículos susceptibles de relacionarse con tal derecho en todo el texto constitucional son cinco: el art. 10 CE, art. 20 CE, art. 23 CE, art. 24 CE y art. 105 CE. La doctrina española en general y autores concretos como DÍEZ PICAZO ${ }^{69}$ o MORENO GONZÁLEZ ${ }^{70}$, como comprobaremos en este capítulo, no son del todo homogéneos a este respecto. Cuando se trata de definir con precisión cuántos y cuáles de los derechos redactados en la CE se han de entender como fundamentales.

En primer lugar, el décimo precepto de la CE viene a condicionar las interpretaciones atendiendo a la valoración internacional que a nuestro país influye. Así, han de citarse el art. 42 de la CDFUE, el Pacto Internacional de los Derechos Civiles y Políticos ${ }^{71}$ aplicado por el Comité de Derechos Humanos de las Naciones Unidas y el Convenio Europeo para la Protección de los Derechos Fundamentales y las Libertades Públicas ${ }^{72}$ aplicado por el TEDH. El anclaje con el principio democrático de la CE, así como la aplicación del apartado segundo del art. 10 CE son los principales elementos aducidos por los autores que defienden esta postura. ${ }^{73}$ Por estas razones puede y debe reconocerse que goza de consideración de fundamental en el campo del derecho internacional público de los derechos humanos.

El anclaje en el art. 20 CE en virtud de la cláusula del expuesto art. 10.2 CE proyecta una interpretación extensiva del apartado b) del primero. Salvando obstáculos doctrinales, sería posible este anclaje y no encontraría parangón ninguno en el TC que no podría pronunciarse en contra de un hipotético futuro derecho fundamental de acceso a la información recogido en una Ley Orgánica de Transparencia tal como pone de manifiesto la historia jurídica respecto a derechos fundamentales emergidos y emergentes. Un ejemplo de esto es la Ley 15/1999 de 13 de septiembre de Protección de Datos $^{74}$ y el derecho a la intimidad anclado en el art. 18.4 CE con mucha menos fijación que la propuesta de anclaje del acceso en el art. $20 \mathrm{CE}$ y sin embargo fue posible. ${ }^{75}$

\footnotetext{
${ }^{68}$ Término que instaura en este campo SÁNCHEZ DE DIEGO en toda su obra en alusión al remanecer de un derecho y su desarrollo respecto a los contenidos en la Carta Magna. SÁNCHEZ DE DIEGO FERNÁNDEZ DE LA RIVA, M., El “día después” de la Ley de Transparencia, Revista Jurídica de Castilla y León, núm. 33, 2014, p 6.

${ }^{69}$ DIEZ PICAZO, L., Sistema de derechos fundamentales, Editorial Thomson-Civitas, Madrid, 2005, p. 51.

${ }^{70}$ MORENO GONZÁLEZ, G., "El derecho de acceso a la información pública en la Ley de Transparencia: Una aproximación constitucional”. Eunomía, núm. 8, 2015, p. 99 y ss.

${ }^{71}$ Adoptado y abierto a la firma, ratificación y adhesión por la Asamblea General en su resolución 2200 A (XXI), de 16 de diciembre de 1966.

${ }^{72}$ Hecho en Roma el 4 de noviembre de 1950, y enmendado por los Protocolos adicionales números 3 y 5, de 6 de mayo de 1963 y 20 de enero de 1966 (BOE núm. 243, de 10 de octubre de 1979).

${ }^{73}$ FERNÁNDEZ RAMOS, S., El derecho de acceso a los documentos administrativos, Marcial Pons, Madrid, 1997, pp. 350 y ss.

${ }^{74}$ BOE núm. 298, de 14 de diciembre de 1999.

${ }^{75}$ GUICHOT. E., (coord.), Transparencia, Acceso a la Información Pública y Buen Gobierno. Estudio de la Ley 19/2013, de 9 de diciembre, Tecnos, Madrid, 2014, p. 46.
} 
En cuanto a esta vinculación con preceptos de calidad democrática, los arts. 23 y 24 CE (participación ciudadana en los asuntos públicos y la tutela judicial efectiva), se ha de actuar con más mesura y escepticismo pues las razones de anclaje son más de complemento que de fundamento. La escueta doctrina que aboga por este anclaje la defiende en bloque, complementando al art. 20.1 d) CE, aludiendo al propio contenido del art. 23 CE, en su propia garantía y también en el derecho a un derecho procesal en estrados en los que el acceso a la información es imprescindible. ${ }^{76}$

Finalmente, el anclaje en el art. 105 CE es harto conocido habida cuenta de que ya hemos podido comprobar que antes de la LTBG la única protección y desarrollo a este derecho estaba recogida en el art. 37 LRJPAC (derecho de acceso a Archivos y Registros). Existe aquí un sector de la doctrina como SOTO Y LOSTAL ${ }^{77}$ O EMBID IRUJO $^{78}$ que creen al art. $105 \mathrm{~b}$ ) per se desangelado de todo anclaje imaginable con ninguno de los derechos del Título I y que lo excluye de esa posición por razones conservadoras o geográficas, y lo que no provenga taxativamente de dicho título no puede considerarse fundamental. A día de hoy este, el art. $105 \mathrm{CE}$, ha sido el anclaje escogido por el legislador en lo que algunos podemos opinar que es un derecho muy limitado que no cumple lo contemplado a nivel internacional porque según esa redacción no es toda la información accesible ni por todos accesible que es el objetivo que debería cumplir.

\section{Iusfundamentalización del derecho de acceso desde la vinculación instrumental y como derecho autónomo}

En atención a la tendencia paulatina de la doctrina y el derecho comparado, una manera de entender el derecho de acceso a la información pública se dirige a conceptualizar la obtención de información no como fin en sí mismo, sino como instrumento de concreción de otros derechos constitucionales, valores o principios. ${ }^{79}$ Respecto a esta posición en que se defiende la naturaleza iusfundamental del derecho de acceso a la información pública puede partirse de su inadecuada e insuficiente ${ }^{80}$ naturaleza relacionada con el art. 105. b) CE, lo que recorta la efectividad que la LTBG habría tenido de haberse relacionado con el art. $20 \mathrm{CE}$ como muchos expertos defendían en su fase de anteproyecto de ley. El art. 105. b) CE se ubica en el cuarto título de la carta el cual se destina al "Gobierno y la Administración”, sin embargo son muchos más (Casa

76 BLANES CLIMENT, M.A., La transparencia informativa de las Administraciones Públicas, Thomson-Aranzadi, Cizur Menor, 2014, p. 209.

${ }^{77}$ SOTO LOSTAL, S., El derecho de acceso a la información, Tirant Lo Blanch, Valencia, 2011, pp. 42 y ss.

${ }_{78}$ EMBID IRUJO, A., El derecho de acceso a los archivos y registros administrativos. Algunas reflexiones en las vísperas de sus consagraciones legislativas, La protección jurídica del ciudadano. Estudios en homenaje al profesor Jesús González Pérez, Civitas, Madrid, 1993, p. 732 y ss.

79 "En estos casos la propia existencia del mecanismo de obtención de información, o bien de la obligación de otorgar información, tiene efectos preventivos o institucionales, independientemente del uso que se haga de la propia información”. ABRAMOVICH, V. y COURTIS, C., El acceso a la información como derecho. Anuario de Derecho a la Información, vol. 1, 2000, pp. 143 y ss.

${ }^{80}$ SÁNCHEZ DE DIEGO insiste siempre en que se confunde transparencia con derecho de acceso a la información pública y quizás ahí radique el error de anclaje pues "no se encuentra en el mismo plano de igualdad” uno y otro término. SÁNCHEZ DE DIEGO FERNÁNDEZ DE LA RIVA, M., El "día después” de la Ley de Transparencia, Revista Jurídica de Castilla y León, núm. 33, 2014, p 7.

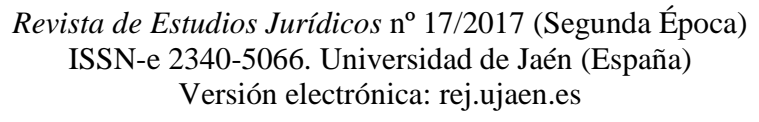


Real, fundaciones o sociedades mercantiles de participación) los sujetos comprendidos en el ámbito subjetivo de aplicación a los que se refiere el art. 2 de la LTBG. Si al ámbito objetivo nos referimos, sigue siendo inadecuado el art. 105. b) CE el cual lo concentra en torno a "archivos y registros" cuando el real objeto de la ley es la "información pública" que existe además de en esos archivos y registros, en otros muchos lugares que se sitúan al margen de la publicidad registral o archivística, pues debe accederse a la información que es el contenido sin pasar por continentes.

Puede hablarse de nuevos argumentos si atendemos a la doctrina generada como consecuencia de la LTBG, y es aquí donde se critica la poca atención prestada a los derechos humanos, el gran ignorado cuando se habla de transparencia en España. Autores iusfundamentalistas del derecho de acceso como OLMEDO se plantean su anclaje constitucional a este respecto. Además el derecho de acceso a la información pública es imprescindible, según OLMEDO, para la formación de una opinión pública que actúa de base para el funcionamiento democrático de la comunidad política. ${ }^{81} \mathrm{De}$ esta forma se situaría al mismo nivel que la libertad de información y de la que participa, según jurisprudencia del TEDH, por lo que debe ser considerado un derecho democrático fundamental y, como tal, debe tener un tratamiento administrativo ${ }^{82}$ más allá del que le otorga la LTBG.

Hemos de concebir en este tramo a la Administración en la faceta que describe el Preámbulo del Convenio del Consejo de Europa sobre el Acceso a los Documentos Públicos de 18 de junio de $2009^{83}$. Si bien es cierto que el derecho de acceso a la información no se ha caracterizado históricamente por ser uno de los que han supuesto de forma directa y clara unas discriminaciones o diferencias sociales que hayan sido objeto de reivindicación por aquellos más desfavorecidos en la sociedad, podemos poner en duda que si consideramos que aunque de manera indirecta este derecho condiciona con un carácter instrumental la posibilidad de gozar o acceder a

\footnotetext{
${ }^{81}$ OLMEDO concluye en su trabajo que: "El derecho de acceso es un derecho fundamental y no un derecho administrativo...es un presupuesto capital de formación de la opinión pública, base fundamental del funcionamiento democrático de una comunidad política, al mismo nivel que la libertad de información y de la que forma parte según los textos internacionales en la materia y la jurisprudencia del TEDH. Su regulación como derecho meramente administrativo lo deja huérfano de la protección de los fundamentales, y prejuzga en su contra la ponderación de intereses que deberá realizarse administrativa y judicialmente para resolver los previsibles conflictos con otros derechos”. OLMEDO PALACIOS, M., “La Ley 19/2013, de 9 de diciembre, de transparencia, acceso a la información y buen gobierno”, Diario La Ley, núm. 8237, 27 de enero de 2014.

82 MILANS DEL BOSCH, S., “Más transparencia en la gestión administrativa pública”, Blog Cuatrecasas, 2 de Junio de 2015. Disponible en: http://cuatrecasasblog.com/2015/mas-transparencia-enla gestionadministrativa-publica (Consultado el 11/9/16).

${ }^{83}$ La cual afirma que "el ejercicio del derecho de acceso a los documentos públicos proporciona una fuente de información para el público y ayuda al público a formarse una opinión sobre el estado de la sociedad y sobre las autoridades públicas”. Disponible en: http://www.oas.org/es/sla/ddi/docs/acceso_informacion_desarrollos_convenio_consejo_europeo.pdf (Consultado el 17/5/17).
} 
determinados derechos que pueden significar en la práctica una indudable fuente de desigualdades sociales.

Si el art. 20.1.d) CE reconoce y protege el derecho "a comunicar o recibir libremente información veraz por cualquier medio de difusión” garantizando la libertad de recibir y comunicar información, puede justificarse que en la expresión "derecho a la información” se encuentra implícita la facultad de estar informados, de buscar y de tratar de conocer la información interpretando este precepto a través de la Declaración Universal de Derechos Humanos y del Pacto Internacional de Derechos Civiles y Políticos que sí que reconocen la facultad de investigar o buscar. Del mismo modo, el art. 20.1.a) CE protege el derecho "a expresar y difundir ideas y opiniones”, las cuales, para ser fundadas, deben basarse en el derecho a la verdad, a la información veraz como se ha mencionado en numerosas ocasiones. Por tanto, la información y la posibilidad de acceder a ella juega un papel muy importante para el ejercicio del derecho a expresar opiniones y la dispensa de información veraz ha de estar como norma en el Estado, siendo la oficialidad el modelo de información veraz y pública.

Es por esta razón por la que no debe hacerse discriminación ${ }^{84}$ situando a determinados sectores de la población en posiciones no solo perjudiciales o desaventajadas, sino abiertamente contrarias a la dignidad de la persona aunque solo sea desde el punto de vista instrumental que el derecho de acceso supone como ya hemos visto respecto de algunos otros derechos fundamentales pues el objeto de la información puede ser cualquier ámbito y la consecución o no de la misma puede condicionar en gran medida la eficacia de los mismos. ${ }^{85}$

Por su parte, el derecho del art. 23 CE “a participar en los asuntos públicos” implica otro vínculo que refuerza la balanza hacia este sector de la CE, el que los ciudadanos se involucren de forma activa en aquellos asuntos que le son de su interés, es decir, la participación ciudadana. Por esto, las instituciones públicas deben facilitar toda la información que posean para que se produzca una participación real y efectiva. Puede decirse que del desarrollo del derecho a la libertad de expresión y de las libertades informativas así como el derecho de participar en los asuntos públicos se ha originado un nuevo derecho de acceso a la información en manos de las administraciones que permitirá a los ciudadanos participar en la sociedad de forma activa gracias a la información que los entes públicos les proporcionen.

\footnotetext{
${ }^{84}$ Recordar lo que el TC dispuso en la STC 168/1986 que "quienes hacen profesión de la expresión de ideas y opiniones o de la comunicación de información los ejercen con mayor frecuencia que el resto de los conciudadanos pero no derivan de ello ningún privilegio y desde luego no el de transformar a su favor, lo que para el común de los ciudadanos es derecho de libertad, en un derecho de prestación....”. Se puede colegir que siguiendo esta interpretación, éste no solo debe ser reconocido a los periodistas sino al resto de los ciudadanos, sin hacer discriminación por la profesión o el oficio de la persona que reciba la información. Sentencia disponible en el BOE núm. 17 del 20 de enero de 1987.
}

${ }^{85} \mathrm{El} \mathrm{TC}$ ha sostenido que el derecho a la intimidad no se circunscribe solamente a la esfera íntima y personal del individuo, sino que puede alcanzar otros ámbitos, tales como el laboral (en este sentido se refiere la STC 12/2012, de 30 de enero o la STC 241/2012, de 17 de diciembre, que se remite a las SSTC 98/2000, de 10 de abril o 186/2000, de 10 de julio.

\author{
Revista de Estudios Jurídicos n 17/2017 (Segunda Época) \\ ISSN-e 2340-5066. Universidad de Jaén (España) \\ Versión electrónica: rej.ujaen.es
}


La ciudadanía puede alcanzar mejor participación e igualdad cuanta más información tenga y esa labor en la que los poderes públicos deben trabajar para permitir a su vez una mayor participación ciudadana ${ }^{86}$ en la cosa pública sin olvidar que esta labor también se logrará en el otro aspecto del derecho, en cuanto a la no facilitación de determinadas informaciones sensibles o restringidas pues en caso contrario también se podría dar lugar a una discriminación.

Si a garantías para el ciudadano ha de referirse la defensa ha de aludirse a que el art. 105. b) CE se sitúa fuera de la protección que el art. 53 CE ofrece en defensa de sus derechos fundamentales. Con esto se evidencia que el poder de protección no lo ostentaría una jurisdicción de peso como la constitucional sino que recae en primera instancia en órganos administrativos como el CTBG y en última en la jurisdicción contencioso-administrativa. Si se reconoce un anclaje legislativo en el art. 20 CE podría desarrollarse por ley orgánica y gozaría de una garantía constitucional por el proceso de "preferencia y sumariedad" que el 53.2 CE menciona. El reconocimiento de la naturaleza iusfundamental adecúa la posición del derecho de acceso a los niveles de reconocimiento que gozan otros derechos como el de la intimidad ${ }^{87}$. Un valor añadido que tendría este desarrollo es la extensión de sus ventajas a las materias de transparencia y buen gobierno dando sentido a otras normas que regulan estos aspectos junto al de acceso.

Desde el derecho comparado se han ofrecido muchas razones de influencia, de Estados del entorno europeo y de organizaciones internacionales, que empujan a ubicar la relación del derecho de acceso en el derecho a la información atendiendo al art. 10.2 CE. Simplemente recordar que el Pacto internacional de derechos civiles y políticos en su art. 19 se refiere a la libertad de opinión y expresión. Esto también ocurre en la Corte Interamericana de Derechos Humanos, en concreto en la sentencia del caso Claude Reyes contra Chile, del año 2006. Ahí de nuevo se reconoce que en el art. 13 del Pacto Internacional de San José de Costa Rica, la libertad de expresión ampara el derecho de acceso a la información pública. Hoy en día para que exista una opinión pública libre es necesario que las personas puedan acceder directamente y sin cortapisas a la información que se encuentra en manos de los poderes públicos.

Otro de los vínculos adecuados, conjuntamente al art. 20 CE, que permiten naturalizar el acceso en el iusfundamentalismo es el art. 18.4 CE, un precepto que determina la regulación informática en lo que a honor, intimidad y pleno ejercicio de derechos se refiera. Aunque el artículo, por el contexto de la promulgación de la CE, no regula el

\footnotetext{
${ }^{86}$ Según la STC 161/1988, de 20 de septiembre, la participación permite a los ciudadanos comunicarse con el poder público, y potencia la interrelación entre los Parlamentos y los ciudadanos, coopera a que los parlamentarios conozcan las preocupaciones de la sociedad a la que representan, así como las demandas políticas y las opiniones de los individuos y de los actores sociales.

${ }^{87}$ El TC ha sostenido además que el derecho a la intimidad no se circunscribe solamente a la esfera íntima y personal del individuo, sino que puede alcanzar otros ámbitos, tales como el laboral (en este sentido se refiere la STC 12/2012, de 30 de enero o la STC 241/2012, de 17 de diciembre, que se remite a las SSTC 98/2000, de 10 de abril o 186/2000, de 10 de julio).
}

\author{
Revista de Estudios Jurídicos n ${ }^{\circ}$ 17/2017 (Segunda Época) \\ ISSN-e 2340-5066. Universidad de Jaén (España) \\ Versión electrónica: rej.ujaen.es
}


derecho de acceso a internet o a los datos informatizados ${ }^{88}$. Si el desarrollo de las TIC y su generalización en la sociedad fue un hecho de transversalidad que sirvieron para desarrollar todo un derecho fundamental que actualmente tiene un gran arraigo en la ciudadanía, lo mismo ocurre con el aperturismo y la transparencia. Son dos elementos que como la expansión de la era digital, se transversalizan y alcanza a todas las esferas.

En segundo criterio de defensa, la creación de derechos fundamentales se fundamenta en que los derechos fundamentales no son un catálogo blindado, de hecho en España ya se han creado algunos ${ }^{89}$. La posición de la tendencia defendida es histórico-sociológica y parcialmente iuspositivista pues los derechos humanos son aspiraciones de la humanidad, fines a realizar a futuro o demandas que el hombre en la Historia que hace que el momento en que vivimos inundado de nuevas tecnologías e interconexión haga a la humanidad exigir un nuevo derecho, el de acceso a la información. La misma autoridad jurisdiccional en lo constitucional existente ha desarrollado otros derechos fundamentales como el de medios de comunicación y a ejercer el "derecho a gestionar y explotar” información, en concreto la STC 12/1982 de 31 de marzo ${ }^{90}$.

En la presente se ha dar una interpretación de valoración particular de la realidad social como sustento de la defensa del derecho fundamental de acceso pues condiciona nuestra existencia. El contexto propio de los preceptos en lo que a derecho de acceso a la información se refiere siguiendo lo instruido en el art. 3.1 del Código Civil ${ }^{91}$ como pauta interpretativa establece que "las normas se interpretarán según el sentido propio de... la realidad social del tiempo en que han de ser aplicadas...”. El contexto de las TIC, la sociedad interconectada, los antecedentes históricos crecientes y de influencia internacional y la realidad social parecen razones contundentes para reinterpretar este emergente derecho que nos ocupa.

Entrando en criterios, si un derecho fundamental es considerado como tal en la medida en la que pueda constituir medidas de protección integral de la persona, atendiendo a, en palabras de CARBONELL, la preservación de bienes básicos necesarios para poder desarrollar una vida digna. Acierta el autor en este razonamiento pues contrastado con el modelo actual de vida digna, es inimaginable la dignificación de la opacidad, parquedad y ausencia de luz administrativa. Defender la creación de nuevos derechos fundamentales por exigencias de la evolución social supone la creación de nuevos

\footnotetext{
${ }^{88}$ Un ejemplo es el modelo portugués, un antecedente de regulación riguroso del derecho de acceso a través de la constitución el cual en su art. 35 con la rúbrica de "Uso de la informática” reza "1. Todos los ciudadanos tienen derecho a acceder a los datos informatizados que les conciernan, pudiendo exigir su rectificación y actualización...”.

${ }^{89}$ Por ejemplo, el derecho a la protección de datos personales tuvo un desarrollo inicial anterior a la Ley de protección de datos en la famosa Ley orgánica reguladora del tratamiento automatizado de datos personales del año 1992 (BOE núm. 262, de 31 de octubre de 1992).
}

${ }^{90}$ BOE núm. 95, de 21 de abril de 1982. Disponible en: http://hj.tribunalconstitucional.es/es/Resolucion/Show/54 (Consultado el 19/5/17).

${ }^{91}$ BOE núm. 206, de 25 de julio de 1889.

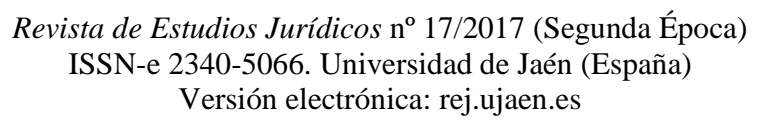


derechos subjetivos públicos ${ }^{92}$ que encajan en la sección de derechos fundamentales y libertades públicas siendo, por algunos autores ${ }^{93}$ y para el que escribe, la libertad de recibir información una libertad pública.

El atacar el iusfundamentalismo desde el origen es muy interesante puesto que tan simple y tan complejo a la vez como estudiar la teoría de los derechos fundamentales e ir línea a línea contrastando su extrapolación al derecho de acceso a la información de donde resulta que todas las premisas se le pueden ajustar. ${ }^{94}$ Desde luego, si en referencia a esto último y como fundamento iusfundamentalista, quiere formarse una nación sensible, comprometida, responsable esta debe ser inconformista y rigurosa con su papel dentro del Estado que es en España tan determinante que se juega el Gobierno Central, Autonómico o Local por la emisión de un voto cada cuatro años con lo que el peso responsable de esta decisión ha de estar contrastada en el conocimiento de las instituciones y el papel de los candidatos a ellas para ejercer una valoración con fundamento.

Encontramos, finalmente, fuertes argumentos si aludimos al dictamen de un órgano consultivo de peso como es el informe previo del Consejo de Estado ${ }^{95}$ sobre el proyecto de ley donde se indican numerosas razones jurídicas tendentes a que debería haber en la misma una referencia al art. $20 \mathrm{CE}$ donde se consagran las libertades públicas

\footnotetext{
92 TORRES cita a GARCÍA DE ENTERRÍA para indicar que los derechos públicos subjetivos consisten en "la posibilidad atribuida al individuo de poner en movimiento una norma jurídica en su propio interés". TORRES DEL MORAL, A., Estado de Derecho y Democracia de Partidos, Universidad Complutense de Madrid, Madrid, 2010, p. 228.

93 TORRES considera que el recibir información es una "manifestación exterior de la libertad humana y que se ejerce en relación con los demás, aunque no necesariamente de forma colectiva, y aspiran a una repercusión extensa en la sociedad”. TORRES DEL MORAL, A., Estado de Derecho y Democracia de
} Partidos, Universidad Complutense de Madrid, Madrid, 2010, p. 234.

94 El propio autor enfatiza que "cuando se habla de derechos fundamentales estamos hablando de la protección de los intereses más vitales de toda persona, con independencia de sus gustos personales, de sus preferencias o de cualquier otra circunstancia que pueda caracterizar su existencia. Por ello se puede decir que los derechos fundamentales deben ser universales porque protegen bienes con los que debe contar toda persona, con independencia del lugar en el que haya nacido, de su nivel de ingresos o de sus características físicas”, CARBONELL. M., El derecho de acceso a la información como derecho fundamental, en Democracia, transparencia y Constitución: propuestas para un debate necesario, UNAM, México, 2006, p. 4.

95 Informe núm. 707/2012 del Consejo de Estado reunido en Comisión Permanente, presidido por Beccaria el 19 de julio de 2012 donde apelaban respecto al anteproyecto de ley que "Este enfoque responde a la importancia que en el contexto actual posee este derecho, que además de estar reconocido en el mencionado artículo constitucional, enlaza con las declaraciones y mandatos contenidos en otros preceptos de la norma fundamental (así, con los artículos 1.1, 9.2, 20 y 10.2, preceptos que habrían de mencionarse expresamente en la exposición de motivos)”. Disponible en: https://www.boe.es/buscar/doc.php?id=CE-D-2012-707 y https://es.scribd.com/doc/105482040/Informe-del-Consejo-Estado-sobre-la-Ley-de-Transparencia (Consultado el 15/5/17). 


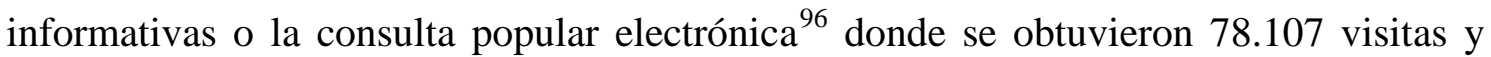
3.669 observaciones. En este último informe, valioso por su cariz democrático y de participación ciudadana, se destaca en su segunda página que existió "Un significativo número de observaciones que señalan la necesidad de configurar el derecho de acceso como un derecho fundamental regulado, por tanto, por una norma de rango orgánico. Para apoyar su argumentación se basan en la configuración como fundamental que tiene el derecho de acceso a la información a nivel internacional (CEDH y CDFUE)”.

Como sugerencia para la construcción y consolidación del derecho de acceso en clave fundamental se propone aplicar una de las fórmulas del constitucionalismo francés, respecto a mencionar al tratado europeo de derechos humanos en el que figura en su articulado el derecho de acceso, lo cual sería suficiente para dar la categoría buscada a la LTBG. Para esto, claro está, sería más que necesaria una consulta plebiscitaria o un referéndum directamente que midiese las inclinaciones populares al respecto de este derecho. En democracia, el peso del principio de las mayorías no ha de despreciarse, donde encontramos una amplia mayoría tendente a este reconocimiento.

\section{IV.- CONCLUSIONES}

En virtud de lo expuesto podemos terminar, respondiendo a las preguntas iniciales, que en España, antes de las medidas de acceso, transparencia y rendición de cuentas iniciadas a partir de 2013 ya existían normas prototransparentes y antecedentes en la materia. Si bien es cierto también que a partir de la LTBG las competencias en la materia son independientes, autónomamente organizadas, más garantistas y están compactadamente reguladas.

Se sostiene también que la consolidación y asentamiento paulatino de la transparencia y el derecho de acceso a la información a lo largo de los años el Estado, incluidas las previas a la entrada en vigor de la LTBG, mediante políticas legislativas, reformas institucionales, planes y las numerosas normativas al respecto de las mismas en cada uno de los Poderes del Estado dirigido a enriquecer la calidad democrática.

El culmen de este proceso se alcanzaría con el desplazamiento de las múltiples manifestaciones constitucionales del derecho de acceso a la información pública a la Sección Primera del Capítulo Segundo del Título Primero CE, y que este reconocimiento consumaría un Estado transparente. Así, puede afirmarse también que el Estado de las Autonomías ha impulsado la transparencia teniendo en cuenta la antelación de muchas CCAA en desarrollar la transparencia en sus propias normas.

Además, desde la proyección de la LTBG en comisiones legislativas, se han planteado nuevos y robustos argumentos desde la doctrina influenciados por las legislaciones en

\footnotetext{
${ }^{96}$ Informe sobre la consulta pública electrónica del anteproyecto de la LTBG de la Secretaría de Estado de Relaciones con las Cortes adscrita al Ministerio de la Presidencia. Informe filtrado por ElDiario.es que queda ofrecido en formato electrónico pero no disponible por organismos oficiales. Disponible en: https://es.scribd.com/doc/105482716/Informe-del-Ministerio-de-Presidencia\#from_embed 25865, consultado el 10/2/17).

(Entrada:
} 
transparencia y constituciones europeas entre otros motivos amparados en la realidad digital. Estos nuevos argumentos marcan una tendencia a la posible consideración del derecho de acceso a la información pública como derecho fundamental.

Se esgrimen dos flancos de defensa a este respecto. Por un lado uno que tiene la iusfundamentalización del derecho de acceso a la información pública por ser este requisito sine qua non de otros derechos fundamentales a los que está vinculado directa o indirectamente y otro flanco que defiende su reconversión como derecho fundamental autónomo. Por tanto y finalmente, puede sostenerse la existencia de un posicionamiento de esta materia que se pronuncia para ofrecer nuevos elementos de argumentación al respecto que abre la puerta a la posibilidad de hacer del derecho de acceso un derecho fundamental.

\section{V.- BIBLIOGRAFÍA}

ABRAMOVICH, V. y COURTIS, C., "El acceso a la información como derecho”. Anuario de Derecho a la Información, vol. 1, 2000.

ALEXY, R., Teoría de los derechos fundamentales, Centro de Estudios Constitucionales, Madrid, 1993.

BLANES CLIMENT, M.A., La transparencia informativa de las Administraciones Públicas, Thomson-Aranzadi, Cizur Menor, 2014.

CARBONELL SÁNCHEZ. M., El derecho de acceso a la información como derecho fundamental, en Democracia, transparencia y Constitución: propuestas para un debate necesario, UNAM, México, 2006.

DIEZ PICAZO, L., Sistema de derechos fundamentales, Editorial Thomson-Civitas, Madrid, 2005.

DÍEZ PICAZO, L., Sobre Secretos Oficiales, Civitas, Madrid, 1998.

EMBID IRUJO, A., El derecho de acceso a los archivos y registros administrativos. Algunas reflexiones en las vísperas de sus consagraciones legislativas, La protección jurídica del ciudadano. Estudios en homenaje al profesor Jesús González Pérez, Civitas, Madrid, 1993.

FERNÁNDEZ RAMOS, S., El derecho de acceso a los documentos administrativos, Marcial Pons, Madrid, 1997.

GUICHOT REINA, E., Transparencia y Buen Gobierno, Estudio y Ley, Aranzadi. Cizur Menor, 2014.

GUICHOT REINA. E., (coord.), Transparencia, Acceso a la Información Pública y Buen Gobierno. Estudio de la Ley 19/2013, de 9 de diciembre, Tecnos, Madrid, 2014.

La normativa autonómica en materia de derecho de acceso a la información pública, Colección Estudios y Documentos de INAP, Madrid, 2016

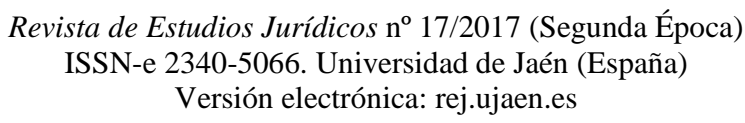


LÓPEZ GUERRA, L., ESPÍN TEMPLADO, E., GARCÍA MORILLO, J., PÉREZ TREMPS, P., Y SATRÚSTEGUI GIL-DELGADO, M., Derecho Constitucional Vol. II, Los poderes del Estado. La organización territorial del Estado, Tirant lo Blanch, Valencia, 2007.

LOZANO MIRALLES, J., “Auditoría pública”, Revista de los Órganos Autónomos de Control Externo, núm. 3, 1995.

LOZANO MIRALLES, J., "El control de las cuentas públicas”, Foro de debate: Revista de Estudios Jurídicos, núm. 14, 2014.

LOZANO MIRALLES, J.,"Órganos de control externo y Parlamento”, Revista de las Cortes Generales, núm. 40, 1997.

MARÍN GÁMEZ, J. A., Naturaleza jurídica del tribunal constitucional. Ariel, 1998.

MENDEL, T. "La libertad de información: derecho humano protegido internacionalmente”, Revista Derecho Comparado de la Información, núm. 1, 2003

MESTRE DELGADO, J., El derecho de acceso a los Archivos y Registros administrativos. Análisis del artículo 105.b) de la Constitución, Civitas, Madrid, 1998.

MOHL, R., Die deutsche Polizei-wissenschaft nach den Grundsätzen des Rechtsstaates. Tübingen, H. Laupp, 1832.

MORENO GONZÁLEZ, G., "El derecho de acceso a la información pública en la Ley de Transparencia: Una aproximación constitucional”. Eunomía, núm. 8, 2015.

OLMEDO PALACIOS, M., "La Ley 19/2013, de 9 de diciembre, de transparencia, acceso a la información y buen gobierno”, Diario La Ley, núm. 8237, 27 de enero de 2014.

PALOMARES HERRERA, M., "Comparative study on transparency and right of access in the international sphere and its influence in Spain”. Ius Humani Law Journal, v. 6, 2017.

PAU I VALL, F., La Transparencia desde el Parlamento. XXI Jornadas de la Asociación Española de Letrados de Parlamentos, Tecnos, Madrid, 2015,

POMED SÁNCHEZ, L., El derecho de acceso de los ciudadanos a los archivos y registros administrativos, INAP, Madrid, 1989.

RAMS RAMOS, L., "La transformación del derecho de acceso en España: de derecho de configuración legal a derecho fundamental”, Revista Española de Derecho Administrativo, núm. 160, octubre-diciembre de 2013.

RIDAO MARTÍN, J., “La transparència i el dret d’accés a la informació pública en la llei catalana 19/2014: Reflexions entorn al seu abast $\mathrm{i}$ al marc competencial en què s’insereix”, Revista para el Análisis del Derecho, núm. 4, 2015. 
RODRIGUEZ ZEPEDA, J., "Estado y transparencia: un paseo por la filosofía política”, Instituto Federal de Acceso a la Información Pública, cuaderno de transparencia 4, 2004.

RUIZ-RICO RUIZ, C., "Breves consideraciones jurídicas en torno a la reciente Ley española de 19/2013, 9 de diciembre, de Transparencia, Acceso a la Información Pública y Buen Gobierno”, Boletín Mexicano de Derecho Comparado, Núm. 140, 2014.

RUIZ-RICO RUIZ, C., “Transparencia y participación en el Derecho Autonómico: un análisis constitucional”, Revista Internacional de Doctrina y Jurisprudencia, 2004, Vol. 6, $\mathrm{n}^{\mathrm{o}} 1$, p. 1.

SAINZ MORENO, F., Secreto y Transparencia, Estudios para reforma de la reforma de la administración pública, INAP. Madrid, 2004.

SALVADOR CRESPO, M., "Retos y oportunidades para el Gobierno local en tiempos de crisis”. Revista Cuadernos Manuel Giménez Abad, no 4, 2012.

SÁNCHEZ DE DIEGO FERNÁNDEZ DE LA RIVA, M., El “día después” de la Ley de Transparencia, Revista Jurídica de Castilla y León, núm. 33, 2014.

SÁNCHEZ DE DIEGO FERNÁNDEZ DE LA RIVA, M., Participación, representación y Democracia, XII Congreso de Constitucionalistas de España, Universidad de Salamanca, 2014.

SÁNCHEZ DE DIEGO FERNÁNDEZ DE LA RIVA, M.., Un derecho fundamental a acceder a la información pública, El derecho de acceso a la información pública, Actas del Seminario Internacional Complutense, Facultad de Ciencias de la Información, Universidad Complutense de Madrid , Madrid, 2008.

SOTO LOSTAL, S., El derecho de acceso a la información, Tirant Lo Blanch, Valencia, 2011.

TORRES DEL MORAL, A., Estado de Derecho y Democracia de Partidos, Universidad Complutense de Madrid, Madrid, 2010.

VILLAVERDE MENÉNDEZ, I., Derecho a ser informado y el artículo 20.1 de la Constitución Española, Estudios de Derecho Público en Homenaje a Ignacio de Otto, Universidad de Oviedo, 1993.

WENCER, E., KOLLING, M., Y RAGONE, S. "La Ley de Transparencia, Acceso a la Información y Buen Gobierno”, Centro de Estudios Políticos y Constitucionales, Cuaderno 236, 2007. 